\title{
A comprehensive first-principles study of pure elements: Vacancy formation and migration energies and self-diffusion coefficients
}

\author{
Shun-Li Shang, * Bi-Cheng Zhou, William Y. Wang, Austin J. Ross, Xuan L. Liu, Yong-Jie Hu, \\ Hua-Zhi Fang, Yi Wang, and Zi-Kui Liu \\ Department of Materials Science and Engineering, The Pennsylvania State University, \\ University Park, Pennsylvania 16802, USA \\ * Corresponding author. \\ E-mail address: sus26@psu.edu (S. L. Shang).
}

\begin{abstract}
:
A vast number of materials properties and phenomena are regulated by diffusion. However, diffusion coefficients from experiments and calculations are far from complete. Here, we report a compilation of vacancy formation energies $\left(H_{\mathrm{Va}}^{\mathrm{F}}\right)$, vacancy migration energies $\left(H_{\mathrm{Va}}^{\mathrm{M}}\right)$, vacancy activation energies $\left(H_{\mathrm{Va}}^{\mathrm{Q}}\right)$, vacancy concentrations $\left(C_{\mathrm{Va}}\right)$, and vacancy-mediated self-diffusion coefficients $\left(D_{\mathrm{Va}}\right)$ as a function of temperature for 82 pure elements in bcc, fcc, and hcp structures by means of a comprehensive first-principles study. We assess the accuracy of four exchange-correlation (X-C) functionals for first-principles calculations, including the local density approximation (LDA), two generalized gradient approximations (PW91 and PBE), and PBEsol - the focus of the present work. To gain temperature-dependent diffusion properties, transition state structure searches are performed by the climbing image nudged elastic band
\end{abstract}


method; and the needed equilibrium properties of energy $\left(E_{0}\right)$, volume $\left(V_{0}\right)$, bulk modulus $\left(B_{0}\right)$ and its pressure derivative $\left(B^{\prime}\right)$ for each structure of each element are estimated via an energy versus volume equation of state. Examination of the predicted quantities and available experimental data indicates that (i) PBEsol is a better selection in terms of getting accurate equilibrium and diffusion properties; (ii) the facility of vacancy migration can be understood from the redistribution of differential charge density, and anomalous energy pathways for vacancy migration are found for hcp $\mathrm{Ce}, \mathrm{La}, \mathrm{Pr}, \mathrm{Ti}$, and $\mathrm{Zr}$ within the basal plane; (iii) $H_{\mathrm{Va}}^{\mathrm{Q}}$ can be predicted well from the melting point of a pure element and in particular a new relationship $\left(H_{\mathrm{Va}}^{\mathrm{Q}}=B_{0} V_{0} / 6\right)$, suggesting diffusivity is governed by interatomic bonding strength; and (iv) the computed quantities such as $C_{\mathrm{Va}}, D_{\mathrm{Va}}, H_{\mathrm{Va}}^{\mathrm{F}}, H_{\mathrm{Va}}^{\mathrm{M}}$, and $H_{\mathrm{Va}}^{\mathrm{Q}}$ are in favorable accord with available experiments for most elements, but fall short for entropy-related properties. The present study of pure elements provides not only diffusion-related properties and a new understanding of diffusivity, but also a benchmark of first-principles calculations and a foundational dataset for the Materials Genome Initiative.

\section{Keywords:}

Pure elements

Vacancy formation energy

Vacancy activation energy

Self-diffusion coefficient

First-principles calculations 


\section{Introduction}

Diffusivity measures the intermingled motion of atoms or molecules due to thermal excitations [1]. As a consequence, diffusion regulates a vast number of materials properties and phenomena during materials synthesis and when a material is in-service, for example, mass transfer, materials ductility, composition segregation, phase transitions, oxidation, corrosion, creep, fatigue, and fracture. The thermally activated process of diffusion can be described by a migrating atom passing through an energy barrier from a local energy minimum site to an adjacent vacant site [2], with the decisive role being vacancy formation and migration energies/enthalpies ( $H_{\mathrm{Va}}^{\mathrm{F}}$ and $H_{\mathrm{Va}}^{\mathrm{M}}$, respectively) for substitutional solutions and the present focus of pure elements $[1,3]$.

The temperature dependence of vacancy concentration $\left(C_{\mathrm{Va}}\right)$ or of the diffusion coefficient $\left(D_{\mathrm{Va}}\right)$ is frequently, but certainly not always [4], found to obey the Arrhenius equation [1, 3, 5, 6],

$$
\begin{gathered}
C_{\mathrm{Va}}=A_{\mathrm{Va}}^{\mathrm{C}} \exp \left(\frac{-H_{\mathrm{Va}}^{\mathrm{F}}}{k_{\mathrm{B}} T}\right) \\
D_{\mathrm{Va}}=A_{\mathrm{Va}}^{\mathrm{D}} \exp \left(\frac{-H_{\mathrm{Va}}^{\mathrm{Q}}}{k_{\mathrm{B}} T}\right)
\end{gathered}
$$

where $A$ is a pre-exponential factor or the entropy $(S)$ related parameter with $A=\exp \left(S / k_{\mathrm{B}}\right), H$ the enthalpy (the symbol $Q$ is also frequently used in the literature $[3,5,6]), k_{\mathrm{B}}$ the Boltzmann constant, and $T$ the absolute temperature. Specifically, $A_{\mathrm{Va}}^{\mathrm{C}}$ represents the maximum vacancy concentration (when $T \rightarrow \infty$ ), and $A_{\mathrm{Va}}^{\mathrm{D}}$ represents the frequency factor of diffusion, i.e., the maximum diffusion coefficient. $H_{\mathrm{Va}}^{\mathrm{Q}}$ is the vacancy activation energy/enthalpy of diffusion. For the case of substitutional solutions and the present case of self-diffusion, 
Despite numerous experimental methods developed, such as the well-established positron annihilation spectroscopy to determine $C_{\mathrm{Va}}$ [7] and the most reliable tracer sectioning techniques to determine $D_{\mathrm{Va}}$ [3], it is not trivial to measure diffusion-related properties at high temperatures. This is due to difficulties caused by corrosion, oxidation, and contamination of the specimen. As a result, measured data are scattered and very limited $[3,5,6]$, see experimental data for pure elements listed in Supplemental Materials. For example, in bcc V measured values of $A_{\mathrm{Va}}^{\mathrm{D}}$ are scattered in the range of $0.1 \sim 214 \mathrm{~cm}^{2} \mathrm{~s}^{-1}$ and $H_{\mathrm{Va}}^{\mathrm{Q}}=2.82 \sim 4.24 \mathrm{eV}$ [6]. As another example, in hcp Ti [8] the measured values of $H_{\mathrm{Va}}^{\mathrm{Q}}(\perp c$-axis) are $3.14 \mathrm{eV}$ and $2.0 \mathrm{eV}$ for pure and less pure specimens, respectively. Correspondingly, the $A_{\mathrm{Va}}^{\mathrm{D}}$ values of hcp Ti are also scattered, i.e., 13.5 $\mathrm{cm}^{2} \mathrm{~s}^{-1}$ and $1.7 \times 10^{-4} \mathrm{~cm}^{2} \mathrm{~s}^{-1}$ for pure and less pure specimens, respectively.

Compared with the experimental difficulty to determine diffusion properties, computational materials science, especially the one from first-principles calculations, offers powerful tools to provide fundamental understanding of materials behaviors and supports the design of materials that meet a wide range of application requirements $[9,10]$. Relevant to the present work, $H_{\mathrm{Va}}^{\mathrm{F}}$ has been widely studied from first-principles for pure elements. For example, Nazarov et al. [7] predicted the $H_{\mathrm{Va}}^{\mathrm{F}}$ values for $12 \mathrm{fcc}$ metal elements in terms of four exchange-correction (X-C) functionals: the local density approximation (LDA) [11], the generalized gradient approximations (GGA) by Perdew-Wang (PW91) [12, 13] and by Perdew-Burke-Ernzerhof (PBE) [14], and an improved GGA designed to describe point defects by Armiento-Mattsson (AM05) [15]. Nazarov et al. [7] concluded that (a) the predicted $H_{\mathrm{Va}}^{\mathrm{F}}$ values show a strong dependence on the selected $\mathrm{X}-\mathrm{C}$ functional due to the different methods used to describe the 
internal surface created by vacancy; (b) $H_{\mathrm{Va}}^{\mathrm{F}}$ values from LDA and AM05 show similar results and are close to experiments; and (c) an accurate prediction of $H_{\mathrm{Va}}^{\mathrm{F}}$ needs an error correction. Medasani et al. [16] employed five X-C functionals: LDA, PBE, PW91, the revised PBE with a reduced gradient dependence for solids and surfaces (PBEsol) [17], and the meta-GGA of the revised-TPSS [18] to study $H_{\mathrm{Va}}^{\mathrm{F}}$ for 34 bcc, fcc, and hcp metal elements. Medasani et al. [16] drew similar conclusions to those from Nazarov et al. [7], pointing out the $H_{\mathrm{Va}}^{\mathrm{F}}$ values follow the trend of "revised-TPSS > PBEsol LDA > PBE > PW91", and the results from the first three (revised-TPSS, PBEsol, and LDA) show a better agreement with experiments. A more complete $H_{\mathrm{Va}}^{\mathrm{F}}$ study of pure elements was performed by Angsten et al. [19] using PBE for 49 elements in the fcc structure and 44 in the hcp structure, indicating that the $H_{\mathrm{Va}}^{\mathrm{F}}$ values can be explained by properties related to the bonding strength such as the bulk modulus and the cohesive energy. It was also found that the $H_{\mathrm{Va}}^{\mathrm{F}}$ values for some fcc elements (e.g., $\mathrm{Au}, \mathrm{Rh}, \mathrm{Pd}$, and Pt) show large discrepancies $\left(>0.5 \mathrm{eV}\right.$ ) between predictions and experiments $[7,16]$. An improved $H_{\mathrm{Va}}^{\mathrm{F}}$ prediction appeals to the more reliable X-C functionals [20]. For example, Xing et al. [20] indicated that a hybrid HSE functional predicts well the $H_{\mathrm{Va}}^{\mathrm{F}}$ values of $\mathrm{Cu}, \mathrm{Ag}$, and $\mathrm{Au}$. It should be remarked that the ability of different $\mathrm{X}-\mathrm{C}$ functionals to predict $H_{\mathrm{Va}}^{\mathrm{F}}$ stems from an internal free surface created by a vacancy, and $H_{\mathrm{Va}}^{\mathrm{F}}$ can be calculated satisfactorily using an X-C functional without a density gradient (such as LDA) or by using a correction to the density gradient (such as PBEsol and AM05) $[7,16,21]$. Note that the $H_{\mathrm{Va}}^{\mathrm{F}}$ values from AM05 and PBEsol are similar $[7,16]$. Note also that the reason LDA predicts a better $H_{\mathrm{Va}}^{\mathrm{F}}$ is due to a wellknown cancellation effect [7]: LDA overestimates the exchange energy of a free metal surface but underestimates approximately the same magnitude of the correlation energy, resulting in a reasonable net total value of the surface energy. However, for a normal GGA, such as PBE, the 
exchange surface energy is underestimated but the correlation surface energy is only slightly overestimated, resulting in smaller vacancy formation energies [7]. Besides changing the X-C functional, another strategy to improve the $H_{\mathrm{Va}}^{\mathrm{F}}$ prediction is to use the temperature dependent (Gibbs) energy in terms of the quasiharmonic and/or the anharmonic approach [4, 22, 23].

In addition to $H_{\mathrm{Va}}^{\mathrm{F}}$, the vacancy migration energy $H_{\mathrm{Va}}^{\mathrm{M}}$ is another parameter used to determine the diffusion coefficient, but it is relatively less explored. A large study was performed by Angsten et al. [19] to predict $H_{\mathrm{Va}}^{\mathrm{M}}$ for pure elements (49 in the fcc structure and 44 in the hcp structure) by means of PBE and the climbing image nudged elastic band (CINEB) method [24]. Most firstprinciples calculations of $H_{\mathrm{Va}}^{\mathrm{F}}$ and $H_{\mathrm{Va}}^{\mathrm{M}}$, including the aforementioned ones $[7,16,19,20]$, have been performed at $0 \mathrm{~K}$. Only a few first-principles efforts were carried out to investigate the entropy-related parameter $A$ and the enthalpy $H$ at finite temperatures, see Eqs. (1) and (2). For example, the vacancy formation Gibbs energies of $\mathrm{Al}$ and $\mathrm{Cu}$ as a function of temperature, $G_{\mathrm{Va}}^{\mathrm{F}}\left(=H_{\mathrm{Va}}^{\mathrm{F}}-T S_{\mathrm{Va}}^{\mathrm{F}}\right)$, were studied in Neugebauer's group [4, 23]. We developed approaches for predicting the self and impurity diffusion coefficients in $\mathrm{Al}, \mathrm{Cu}, \mathrm{Fe}, \mathrm{Mg}, \mathrm{Ni}$, and $\mathrm{Ti}$ alloys with bcc, fcc, or hcp structure based on the vacancy-mediated diffusion mechanism [2, 8, 25-34], where the required vibrational properties were predicted from phonon calculations and/or the Debye model [35].

\footnotetext{
Attention should be paid to the fact that the vacancy formation energy $H_{\mathrm{Va}}^{\mathrm{F}}$ can be described well by the X-C functionals without a density gradient (i.e. LDA). On the other hand, GGA is the best $\mathrm{X}-\mathrm{C}$ functional to use when obtaining the equilibrium and vibrational properties for metallic systems [36]. This makes the X-C functional PBEsol, a revised GGA with a reduced gradient
} 
dependence for solids and surfaces [17], one of the best choices when predicting temperaturedependent diffusion properties.

Despite efforts from first-principles calculations (see above), a systematic study of pure elements concerning the temperature-dependent diffusivity is still far from complete, motivating the present first-principles study for 82 pure elements in the commonly observed bcc, fcc, and hcp structures. Besides knowledge of diffusion properties, the present work is also a benchmark to examine the capability of first-principles calculations in predicting diffusion-related properties. In addition, the obtained properties of pure elements can serve as a starting point to model diffusion properties for multi-component systems using the general CALPHAD modeling approach [36-39], since in CALPHAD modeling the energetics of phases need to be defined using lattice stabilities, which include both stable and unstable structures of elements.

To achieve the aforementioned goals, vacancy-mediated self-diffusion coefficients as a function of temperature will be predicted for 82 pure elements in terms of the transition state theory (Eyring's reaction rate theory [40] used herein), the CINEB method [24] (to determine the transition state), and the quasiharmonic Debye model [35] (for vibrational thermodynamics at finite temperatures), see details in Section 2. In Section 3, we present the equilibrium properties of volume and bulk modulus from four X-C functionals of LDA, PW91, PBE, and PBEsol. Following this, the vacancy formation energy, vacancy migration energy, vacancy activation energy, vacancy concentration, and self-diffusion coefficient of pure elements are presented, discussed, and understood using their cohesive energy, shear modulus, bulk modulus, melting 
point, and differential charge density. Finally, in Section 4 the conclusions are drawn for the present work.

\section{Methodology}

\subsection{Self-diffusion coefficient and first-principles thermodynamics}

Dominant diffusion mechanisms in alloys and compounds are based on vacancies and interstitial sites with the former mostly for substitutional solutions (the present case) and the latter for interstitial solutions. The process of vacancy-mediated diffusion primarily involves two steps: formation of a vacancy adjacent to the diffusing species and migration of vacancies to the site of the diffusing species. Mono-vacancy mechanism is dominant [3, 41] and will be used in the present work. The (self-)diffusion coefficient $D_{\mathrm{Va}}$ at a given direction is given by [3, 41],

$$
D_{\mathrm{Va}}=\frac{1}{2} f\left\langle d^{2}\right\rangle Z w C_{\mathrm{Va}}
$$

where $f$ is a correlation factor, $\left\langle d^{2}\right\rangle$ the component of the migration distance contributing to diffusion in a specific direction, $Z$ the number of possible migration directions, $C_{\mathrm{Va}}$ the vacancy concentration, and $w$ the jump frequency. For bcc and fcc lattices [41],

$$
D_{\mathrm{Va}}=f a^{2} w C_{\mathrm{Va}}
$$

where $a$ is the lattice parameter and $f=0.72722$ and 0.78146 for bcc and fcc lattices, respectively [41]. For the hcp lattice, there are two independent self-diffusion coefficients perpendicular $\left(D_{\perp}\right)$ and parallel $\left(D_{/ /}\right)$to the $c$-axis. These are as follows $[8,41]$,

$$
\begin{aligned}
& D_{\perp}=\frac{1}{2} C_{\mathrm{Va}} a^{2}\left(3 f_{\mathrm{Ax}} w_{\mathrm{A}}+f_{\mathrm{Bx}} w_{\mathrm{B}}\right) \\
& D_{/ /}=\frac{3}{4} C_{\mathrm{Va}} c^{2} f_{\mathrm{Bz}} w_{\mathrm{B}}
\end{aligned}
$$


where $a$ and $c$ are lattice parameters, $w_{\mathrm{A}}$ and $w_{\mathrm{B}}$ are the jump frequencies perpendicular (jump A) and parallel (jump B) to the $c$-axis. $f_{\mathrm{Ax}}, f_{\mathrm{Bx}}$, and $f_{\mathrm{Bz}}$ are the partial jump correlation factors for jumps A and B perpendicular (marked as $\mathrm{x}$ ) and parallel (marked as $\mathrm{z}$ ) to the $c$-axis, respectively, which are functions of the $w_{\mathrm{A}} / w_{\mathrm{B}}$ ratio given by Mullen [42] graphically for the hcp lattice. The vacancy concentration $C_{\mathrm{Va}}$ can be calculated from the vacancy formation Gibbs energy $G_{\mathrm{Va}}^{\mathrm{F}}$,

$$
C_{\mathrm{Va}}=\exp \left(-\frac{G_{\mathrm{Va}}^{\mathrm{F}}}{k_{\mathrm{B}} T}\right)
$$

where $G_{\mathrm{Va}}^{\mathrm{F}}\left(=H_{\mathrm{Va}}^{\mathrm{F}}-T S_{\mathrm{Va}}^{\mathrm{F}}\right)=G_{\mathrm{IS}}-[(N-1) / N] G_{\mathrm{PS}}$ with $G_{\mathrm{PS}}$ as the Gibbs energy for the perfect state (PS) without a vacancy, $G_{\text {IS }}$ the Gibbs energy for the initial state (IS) with one vacancy, and $N$ the total number of atoms within the PS supercell. The jump frequency $w$ of the migrating atom can be calculated according to Eyring's reaction rate theory [40] with details given in [2, 43],

$$
w=\frac{k_{\mathrm{B}} T}{h} \exp \left(-\frac{G_{\mathrm{TS}}-G_{\mathrm{IS}}}{k_{\mathrm{B}} T}\right)
$$

where $h$ is Plank's constant and $G_{T S}$ the Gibbs energy of the transition state (TS) after ignoring contributions from unstable vibrational modes. It is worth mentioning that Eyring's reaction rate theory assumes that a diffusive jump proceeds over a TS and is in thermodynamic equilibrium with its surrounding. Therefore, the jump frequency can be determined by (i) the ratio of the partition functions of the TS and the IS as well as the diffusion activation energy; and (ii) the mean velocity of the reactants crossing the TS [43]. The simplified form of Eyring's reaction rate theory is Eq. (9), where the inputs are only the Gibbs energies $\left(G_{\mathrm{TS}}\right.$ and $\left.G_{\mathrm{IS}}\right)$ without the complex frequency terms [2]. 
Eqs. (4) to (9) indicate that the key to determine the self-diffusion coefficient and vacancy concentration is the Gibbs energies of the PS, IS, and TS structures. In the present work, the TS structure, i.e., the saddle point structure, and the associated minimum energy pathways were computed by the CINEB method [24] with 3 images employed for the bcc and fcc lattices and 5 for the hcp lattice due to the anomalous energy pathway of vacancy migration which might exist in the hcp lattice [8]. The Helmholtz energy $F$ of a given structure under volume $V$ and temperature $T$, which equals to the Gibbs energy $G$ at zero external pressure in the present case, is determined according to the first-principles quasiharmonic approach [35, 44],

$$
F(V, T)=E_{\mathrm{c}}(V)+F_{\mathrm{vib}}(V, T)+F_{\mathrm{el}}(V, T)
$$

where $E_{\mathrm{c}}$ is the static total energy at $0 \mathrm{~K}$ without the zero-point vibrational energy, which is fitted by a four-parameter Birch-Murnaghan equation of state (EOS) [35] in terms of the energy versus volume $(E-V)$ data points from first-principles calculations,

$$
E_{\mathrm{c}}(V)=a_{1}+a_{2} V^{-2 / 3}+a_{3} V^{-4 / 3}+a_{4} V^{-2}
$$

where $a_{1}, a_{2}, a_{3}$, and $a_{4}$ are fitting parameters. Equilibrium properties estimated from this EOS include volume $\left(V_{0}\right)$, energy $\left(E_{0}\right)$, bulk modulus $\left(B_{0}\right)$ and its pressure derivative $\left(B^{\prime}\right)$. In addition, the pressure-volume $(P-V)$ EOS can be deduced from Eq. (11) via $P=-\partial E / \partial V$ [45]. Seven to nine data points within the volume range of $-9 \%<\left(V-V_{0}\right) / V_{0}<9 \%$ were typically used to perform the present EOS fittings. In addition, these $E-V$ and $P$ - $V$ EOS fits can be employed to judge the quality of first-principles calculations by examining the resulting data points, and can be used to avoid the local, instead of the global, energy minimum obtained from structural relaxations only [36]. $F_{\text {vib }}$ and $F_{\text {el }}$ in Eq. (10) relate to the vibrational and thermal electronic contributions to free energy at finite temperatures, respectively, with the key being the number of configurations, i.e. phonon density of states (PDOS) and electronic density of states (EDOS) as a 
function of frequency or energy, respectively. $F_{\mathrm{el}}$ becomes appreciable when the EDOS is high at the Fermi level. Using EDOS from first-principles calculations as input, the estimation of $F_{\mathrm{el}}$ is given simply by Mermin statistics [35, 44],

$$
F_{\mathrm{el}}=E_{\mathrm{el}}-T S_{\mathrm{el}}
$$

The details required to determine the internal energy $E_{\mathrm{el}}$ and entropy $S_{\mathrm{el}}$ are given in [35, 44].

For the sake of simplicity and effectiveness due to the considerable number of calculations needed for the present pure elements, $F_{\text {vib }}$ is estimated by the Debye-Grüneisen model with the key being the Debye temperature $\Theta_{D}$ for the structure of interest [35, 46],

$$
\Theta_{\mathrm{D}}=s K V_{0}^{1 / 6}\left(\frac{B_{0}}{M}\right)^{1 / 2}\left(\frac{V_{0}}{V}\right)^{\gamma}
$$

where $K$ is a constant [35] and $M$ the atomic mass. The Grüneisen constant $\gamma$ is computed from $B$ ' and the high temperature case is adopted herein [35]. The required equilibrium properties $\left(V_{0}, B_{0}\right.$, and $B^{\prime}$ ) are obtained from Eq. (11). $s$ is a scaling factor needed to adjust $\Theta_{D}$ and $s=0.617$ was suggested by Moruzzi et al. [46] based on the nonmagnetic cubic metals. For stable and metastable pure elements according to the calculated elastic constants at $0 \mathrm{~K}[36], s$ can be estimated from Poisson's ratio (v) [45, 47],

$$
s(v)=3^{5 / 6}\left[4 \sqrt{2}\left(\frac{1+v}{1-2 v}\right)^{3 / 2}+\left(\frac{1+v}{1-v}\right)^{3 / 2}\right]^{-1 / 3}
$$

where the $v$ values may be determined from predicted elastic constants at $0 \mathrm{~K}$ [36]. Such calculated $v$ values are listed in the Supplemental Excel file. A constant scaling factor $s$ is hence adopted in the present work for the sake of simplicity. Eq. (14) works only for stable and metastable phases with $-1<v<0.5$, while unstable phases often possess unrealistic Poisson's 
ratio such as $v<-1$ or $v<0.5$. In this case $s=0.617$ will be employed as a rough alternative for unstable phases.

\subsection{Details of first-principles calculations}

All first-principles calculations in the present work were performed by the VASP 5.3 code [48, 49] with the ion-electron interaction described by the full potential frozen-core projectoraugmented wave method [50] and the X-C functionals depicted by LDA [11], PBE [14], and PBEsol [17]. In addition, the results from PW91 [12, 13], calculated previously [36], were also included in the discussion. It should be mentioned that the LDA functionals are not available for the La-series $f$-elements in VASP (from Ce to Lu), and we hence ignored the LDA calculations for these elements. According to our previous studies [2, 8, 25, 29-32], the following supercells were employed in the present work: (i) a 54-atom $3 \times 3 \times 3$ supercell (similarly, total atoms refer to the PS structure hereafter) with respect to the conventional bcc lattice; (ii) a 64 -atom $4 \times 4 \times 4$ supercell with respect to the primitive fcc lattice; and (iii) a 64 -atom $4 \times 4 \times 2$ supercell with respect to the conventional hcp lattice (or a 96-atom $4 \times 4 \times 3$ supercell for the elements $\mathrm{S}$, Se, and Te in the hcp lattice). The VASP recommended valence states were adopted for each element, see details listed in Table 1.

During VASP calculations, the cutoff energy on the wave functions was taken as 1.4 times higher than the VASP default energy for each element. In general, the $4 \times 4 \times 4 k$-point mesh was used for structural relaxations in terms of the Methfessel-Paxton technique [51] and the $6 \times 6 \times 6 k$ point mesh was used for the final static calculations to obtain accurate energy and electronic structure in terms of the linear tetrahedron method including Blöchl corrections [52]. Energy 
convergence criterion for electronic self-consistency was at least $10^{-6} \mathrm{eV}$ per atom. For the elements $\mathrm{Mn}, \mathrm{Fe}, \mathrm{Co}, \mathrm{Ni}, \mathrm{Br}, \mathrm{Ru}, \mathrm{Rh}, \mathrm{Pd}, \mathrm{Cd}, \mathrm{La}, \mathrm{Ce}, \mathrm{Pr}, \mathrm{Nd}$, Ir, Ac, U, and Np, spin-polarized calculations were performed based on our previous tests using ferromagnetic configuration [36, 53]. Note that the present work does not consider the effects of magnetic phase transitions and other magnetic configurations, such as antiferromagnetism for $\mathrm{Cr}$ and $\mathrm{Eu}$, on diffusion properties at high temperatures for the sake of simplicity. The same first-principles settings were used to perform the normal VASP calculations and CINEB calculations. It should be remarked that the TS structures obtained from CINEB calculations are unstable, which were used directly (i.e., without further relaxations) to calculate the final static energy and electronic DOS.

\section{Results and discussion}

A complete list of equilibrium properties from the $E-V$ EOS of Eq. (11) is given in the Excel file in Supplemental Materials for each available structure (PS, IS, or TS) of each pure element (in the bcc, fcc, or hcp structure). This Excel file contains the present first-principles results from LDA, PBE, and PBEsol, the previous first-principles results from PW91 [36], and experimental data from $[36,54,55]$. As mentioned previously, a few results were obtained from the $P$ - $V$ EOS fittings when the $E-V$ data points are scattered. Detailed notes are given in the Supplemental Excel file for these EOS properties $\left(V_{0}, E_{0}, B_{0}, B^{\prime}\right.$, and the lattice parameters $a$ and $\left.c\right)$ and the fitting qualities. In addition, calculated and experimental data used to plot all the figures are given in the Supplemental Materials or in the present tables. Concerning the suggested/selected experimental data listed in the present tables and used to plot the present figures, two cases are considered: (a) the recommended data from the handbooks, such as the Landolt-Börnstein handbook [6], and (b) the average values. All other data are listed in the Supplemental Materials. 


\title{
3.1. Equilibrium properties for PS structures
}

Equilibrium properties for the PS as well as for other structures are not the present focus. A detailed discussion is hence ignored, but the results are given in the Excel file in Supplemental Materials for the interested reader. More discussions concerning the properties of $V_{0}, E_{0}, B_{0}$, and $B^{\prime}$ from PW91 can be found in $[36,53]$ for pure elements in the bcc, fcc, and hcp structures. All these properties $\left(V_{0}, E_{0}, B_{0}\right.$, and $\left.B^{\prime}\right)$ are the necessary for the Debye model to predict thermodynamic properties at finite temperatures. As an examination, Debye temperatures computed using Eqs. (13) and (14) and the equilibrium properties from PBEsol are plotted in Supplemental Figure S1 for pure elements in their room temperature structures (see Table 1), showing that the Debye temperatures can be predicted well for pure elements using the present model.

\begin{abstract}
As one example, a figure in Supplemental Materials (Figure S2) is plotted to show a comparison of equilibrium volumes $\left(V_{0}\right)$ from LDA, PBE, and PW91 of pure elements in the bcc PS structure with respect to those of $V_{0}$ from PBEsol. The large $V_{0}$ differences from different $\mathrm{X}$-C functionals indicate less believable first-principles calculations. As expected, the Supplemental Figure S2 shows that the $V_{0}$ values from PW91 and PBE are close to each other, and the $V_{0}$ values from PBEsol are roughly in the middle of those from LDA and GGA (PW91 and PBE), but slightly closer to the LDA results. These results suggest that the X-C functional of PBEsol could, to some extent, improve the issues of over binding from LDA and under binding from GGA (see more discussion below).
\end{abstract}


As another example, Figure 1 illustrates a comparison of equilibrium volumes $\left(V_{0}\right)$ and bulk modulus $\left(B_{0}\right)$ of pure elements predicted from LDA, PBE, PW91, and PBEsol, with respect to those from experiments $[36,54,55]$. All these data are given in the Supplemental Materials, and Figure 1 shows only first-principles results at $0 \mathrm{~K}$ for pure elements possessing the bcc, fcc, or hcp structure at room temperature (indicated in Table 1). Similar conclusions can be drawn as from the general first-principles practices: LDA predicts a lower $V_{0}$ but a higher $B_{0}$, and vice versa for GGA (PW91 and PBE). Examination of the experimental $V_{0}$ and $B_{0}$ results indicates that the GGA-related X-C functionals (PW91, PBE, and PBEsol) are generally better than LDA for pure elements. Figure 1 also shows that the present X-C functionals are not suitable for the elements $\mathrm{Ac}, \mathrm{Cd}, \mathrm{Ce}, \mathrm{Cr}, \mathrm{Eu}, \mathrm{Ra}$, and $\mathrm{Tl}$ in the bcc, fcc, or hcp structure, where the predicted results of $V_{0}$ and $B_{0}$ have large errors with respect to the experiments.

\subsection{Properties related to vacancy formation energy}

Table 1, Table 2, and Table 3 summarize the calculated vacancy formation energies/enthalpies $\left(H_{\mathrm{Va}}^{\mathrm{F}}\right)$ at $0 \mathrm{~K}$ for the bcc, fcc, and hcp structures, respectively. These calculations were performed by LDA, PBE, and PBEsol. The presently suggested experimental data are also listed when available on the basis of experimental data [3, 5, 6, 8, 56-59] shown in Supplemental Materials. In these tables, we mark the stable and metastable elements indicated by the calculated elastic constants at $0 \mathrm{~K}[36]$; and the elements with either a small energy difference $(<1 \mathrm{meV})$ or a large energy difference (> $4 \mathrm{meV}$ ) between two different mono-vacancy structures (here, a large energy difference is a signal of an unstable structure). These two mono-vacancy structures are, in fact, the initial state structure (the first image) and the final state structure (the last image) for CINEB calculations, they are identical for stable and metastable structures, but not for unstable 
structures. For elements with very scattered volume versus thermal electronic contribution to the Helmholtz energy (see Eq. (10)), only the vibrational contribution by the Debye model is employed to estimate thermodynamic properties at finite temperatures. In general, predicted $H_{\mathrm{Va}}^{\mathrm{F}}$ values from LDA and PBEsol are close to each other, and are larger than those from GGA-PBE (see discussion in Section 1). Most stable and metastable elements according to elastic constants at $0 \mathrm{~K}[36]$ possess positive $H_{\mathrm{Va}}^{\mathrm{F}}$ values and small energy differences $(<1 \mathrm{meV})$ between two different mono-vacancy structures. There are some exceptions. For example, bcc Be is a metastable phase from elastic constants [36] but has a negative $H_{\mathrm{Va}}^{\mathrm{F}}$, indicating the monovacancy structure is more stable.

Figure 2 shows a comparison of $H_{\mathrm{Va}}^{\mathrm{F}}$ computed at $0 \mathrm{~K}$ with first-principles and $H_{\mathrm{Va}}^{\mathrm{F}}$ from available experimental data suggested by the present work (see data in Table 1, Table 2, and Table 3). Computed $H_{\mathrm{Va}}^{\mathrm{F}}$ values agree reasonably well with experiments, especially the results from LDA and PBEsol (see the discussion in Section 1). Large differences between predictions and experiments are found for $\mathrm{Cr}$ and $\mathrm{Fe}$ in the bcc structure, $\mathrm{Ce}, \mathrm{Th}, \mathrm{Au}, \mathrm{Pt}, \mathrm{Pd}$ in the fcc structure, and Re, Ti, and Hf in the hcp structure. These $H_{\mathrm{Va}}^{\mathrm{F}}$ deviations are thought to be due to the employed X-C functionals (e.g. Au, Pt, and Pd in the fcc structure) and the omission of temperature effects on simulations $[4,22]$; on the other hand, it is possible that these $H_{\mathrm{Va}}^{\mathrm{F}}$ deviations are due to experimental methodologies and the purity of samples (e.g., error $>1 \mathrm{eV}$ from experiments for hcp Ti, more examples can be found in Supplemental Materials). Good agreement was found with experimental values of $H_{\mathrm{Va}}^{\mathrm{Q}}$ for most elements (see Section 3.4, for the cases of $\mathrm{Ce}, \mathrm{Cr}, \mathrm{Pd}, \mathrm{Re}$, and $\mathrm{Th})$. This is encouraging for $H_{\mathrm{Va}}^{\mathrm{F}}$, since measurements of $H_{\mathrm{Va}}^{\mathrm{Q}}$ are typically more accurate when compared to $H_{\mathrm{Va}}^{\mathrm{F}}$ and $H_{\mathrm{Va}}^{\mathrm{M}}[3]$. 
In addition to calculating $H_{\mathrm{Va}}^{\mathrm{F}}$ at $0 \mathrm{~K}$ from first-principles directly (see data in Table 1, Table 2, and Table 3), $H_{\mathrm{Va}}^{\mathrm{F}}$ can also be estimated from Arrhenius fitting to data at high temperatures. It is found that there are no obvious $H_{\mathrm{Va}}^{\mathrm{F}}$ differences between first-principles results at $0 \mathrm{~K}$ and these Arrhenius fitting (see Supplemental Figure S3), since enthalpy is generally independent on temperature [60]. Care should be taken when considering non-Arrhenius behaviors, such as those present in magnetic elements due to magnetic phase transitions (ignored in the present work), where $H_{\mathrm{Va}}^{\mathrm{F}}$ values from $0 \mathrm{~K}$ and from Arrhenius fitting are expected to differ.

Empirical models have been proposed in the literature to understand and estimate $H_{\mathrm{Va}}^{\mathrm{F}}$. For instance, one can calculate $H_{\mathrm{Va}}^{\mathrm{F}}$ from from the cohesive energy $\left(E_{\mathrm{coh}}\right)$ [61],

$$
H_{\mathrm{Va}}^{\mathrm{F}}=\frac{1}{3} E_{\mathrm{coh}}
$$

or from the shear modulus $\left(G_{0}\right)$ and equilibrium volume $\left(V_{0}\right)[62]$,

$$
H_{\mathrm{Va}}^{\mathrm{F}}=\frac{1}{4} G_{0} V_{0}
$$

Figure 3 shows a comparison of $H_{\mathrm{Va}}^{\mathrm{F}}$ from first-principles calculations (LDA, PBE, and PBEsol) and from experimental $E_{\mathrm{coh}}$ [55]. Eq. (15) shows rough agreement for most elements with large deviations found for elements such as $\mathrm{Ra}, \mathrm{Eu}, \mathrm{Tm}, \mathrm{Cr}, \mathrm{Au}, \mathrm{Pt}, \mathrm{Ir}$, and $\mathrm{Ra}$, indicating $H_{\mathrm{Va}}^{\mathrm{F}}$ can be understood qualitatively from $E_{\text {coh }}$. Figure 4 illustrates an example regarding the predicted $H_{\mathrm{Va}}^{\mathrm{F}}$ values of pure elements with the fcc structure from PBEsol with respect to those from $G_{0} V_{0} / 4$, where the $G_{0}$ values were calculated from elastic constants [36], see data listed in Supplemental Materials. Most values of $H_{\mathrm{Va}}^{\mathrm{F}}$ in this figure are far from the relationship in Eq. (16). This same conclusion holds for pure elements with the bcc and hcp structures. 


\subsection{Vacancy migration energy}

Table 4 summarizes the vacancy migration energies/enthalpies $\left(H_{\mathrm{Va}}^{\mathrm{M}}\right)$ at $0 \mathrm{~K}$ for pure elements in the bcc, fcc, and hep structures calculated using the $\mathrm{X}-\mathrm{C}$ functional of PBEsol and the CINEB method [24]. Only the results for stable and metastable structures are shown (see Table 1, Table 2, and Table 3), since the CINEB calculations cannot get a converged result for unstable structures even after hundreds of ionic steps and the transition state structure is usually more stable than the initial unstable structure. Similar to other tables, the suggested experimental data are also listed in Table 4 when available (detailed data listed in Supplemental Materials). The 
quality of the predicted $H_{\mathrm{Va}}^{\mathrm{M}}$ values is shown in Figure 6, indicating that the computed quantities agree reasonably well with experimental data, with large deviations (>0.4 eV) for $\mathrm{Ce}, \mathrm{Th}, \mathrm{Re}$, and $\mathrm{Rh}$. Similar to $H_{\mathrm{Va}}^{\mathrm{F}}$, the deviations between calculated and experimental $H_{\mathrm{Va}}^{\mathrm{M}}$ stem from the simulation method, and in particular experimental methodology and the purity of samples. Reasonable confidence in the present results is based on these two aforementioned facts: (i) the predictions of vacancy activation energies $H_{\mathrm{Va}}^{\mathrm{Q}}$ from the present work for most elements are in good agreement with experiments (see Section 3.4, for example, Ce, Re, Rh, and Th) and (ii) the experimental measurements of $H_{\mathrm{Va}}^{\mathrm{Q}}$ are typically more accurate when compared to experimental measurements of $H_{\mathrm{Va}}^{\mathrm{F}}$ and $H_{\mathrm{Va}}^{\mathrm{M}}$.

Figure 7 gives a comparison of the calculated $H_{\mathrm{Va}}^{\mathrm{F}}$ and $H_{\mathrm{Va}}^{\mathrm{M}}$ values, showing that the relationship between $H_{\mathrm{Va}}^{\mathrm{F}}$ and $H_{\mathrm{Va}}^{\mathrm{M}}$ is very weak, but the $H_{\mathrm{Va}}^{\mathrm{F}}$ values are roughly larger than the $H_{\mathrm{Va}}^{\mathrm{M}}$ values, and can be understood approximately via the relationship $H_{\mathrm{Va}}^{\mathrm{M}} \approx 0.43 H_{\mathrm{Va}}^{\mathrm{F}}$ (the linear fitting goodness $\mathrm{R}^{2}=0.59$ ). The present understanding is different from the relationship of $H_{\mathrm{Va}}^{\mathrm{M}} \approx H_{\mathrm{Va}}^{\mathrm{F}}$ in terms of a few experimental data for fcc metals [6]. In comparison with the weak correlation between $H_{\mathrm{Va}}^{\mathrm{F}}$ and $H_{\mathrm{Va}}^{\mathrm{M}}$ for pure elements, the La-series rare earth elements in the hcp structure show clear trends. Figure 8 displays that $H_{\mathrm{Va}}^{\mathrm{F}}$ and $H_{\mathrm{Va}}^{\mathrm{M}}$ (both $\perp$ and $/ / c$-axis) increase with increasing atomic number (from $\mathrm{La}$ to $\mathrm{Lu}$ ); $H_{\mathrm{Va}}^{\mathrm{F}} \gg H_{\mathrm{Va}}^{\mathrm{M}}$; and $H_{\mathrm{Va}}^{\mathrm{M}}(\| c)>H_{\mathrm{Va}}^{\mathrm{M}}(\perp c)$ but $H_{\mathrm{Va}}^{\mathrm{M}}(\| c) \approx H_{\mathrm{Va}}^{\mathrm{M}}(\perp c)$ with increasing atomic number. In addition, Figure 8 shows that the $H_{\mathrm{Va}}^{\mathrm{F}}$ and $H_{\mathrm{Va}}^{\mathrm{M}}$ values of hcp $\mathrm{Yb}$ are beyond (below) the observed trends, suggesting that the present $\mathrm{X}$ C functional of PBEsol is not suitable for $\mathrm{Yb}$ (this may also be true for La). Figure 8 also shows that the $H_{\mathrm{Va}}^{\mathrm{M}}(\perp c)$ values for hcp $\mathrm{La}, \mathrm{Ce}$, and $\mathrm{Pr}$ are close to zero, see the explanation in Figure 9. 
Similar to the cases of elasticity, ideal shear stress, and stacking fault energy [63-68], $H_{\mathrm{Va}}^{\mathrm{M}}$ due to vacancy migration can be understood qualitatively from the redistribution of charge density because (a) the denser the charge density, the stronger the bonding between atoms based on density functional theory; and (b) the non-spherical distribution of charge density retards the redistribution of charge density during vacancy migration, resulting in a larger $H_{\mathrm{Va}}^{\mathrm{M}}$ value. As an example, Figure 9 illustrates the variation of atomic positions for vacancy migration within the basal plane of the hcp lattice from CINEB calculations. Correspondingly, the isosurfaces of the differential charge density $(\Delta \rho)$ contours are plotted for the migrating atom at image 0 (IS structure) and image 3 (TS structure) within the hcp basal plane for the elements Lu, Gd, Pr, and La. Here, the reference or non-interacting charge density is from free atoms calculated using one electronic step, see details in [68]. Figure 9 shows a near spherical distribution of $\Delta \rho$ for the migrating La and Pr atoms at images 0 and 3, indicating an easy redistribution of $\Delta \rho$ during vacancy migration and resulting in a near zero $H_{\mathrm{Va}}^{\mathrm{M}}(\perp c)$ value as shown in Figure 8. However, the non-spherical distribution of $\Delta \rho$ and the large change of $\Delta \rho$ from image 0 to image 3 are observed for $\mathrm{Lu}$ and $\mathrm{Gd}$, indicating difficulty in the redistribution of $\Delta \rho$ during vacancy migration and resulting in a large $H_{\mathrm{Va}}^{\mathrm{M}}(\perp c)$ value as shown in Figure 8. It is worth mentioning that the understanding of vacancy migration energy from $\Delta \rho$ works also for other pure elements. Ancillary calculations were performed for bcc $\mathrm{Li}\left(H_{\mathrm{Va}}^{\mathrm{M}}=0.05 \mathrm{eV}\right.$, see Table 4$)$, fcc $\mathrm{Cu}\left(H_{\mathrm{Va}}^{\mathrm{M}}=\right.$ $0.71 \mathrm{eV}), \mathrm{hcp} \mathrm{Mg}\left(H_{\mathrm{Va}}^{\mathrm{M}}=0.40 \mathrm{eV}\right)$, and hcp Os $\left(H_{\mathrm{Va}}^{\mathrm{M}}=3.35 \mathrm{eV}\right.$, the highest value among all pure elements), see the differential charge density plots in Supplemental Figure S4. Special attention should be paid to hcp Os, where the redistribution of charge density is extremely difficult during vacancy migration. 
The energy pathway of vacancy migration is commonly thought to follow a bell-shaped profile with a TS structure at its peak [8], especially for materials with simple crystallographic structures such as for those pure elements having bcc, fcc, and hcp structures. The present work indicates that five pure elements in the hcp structure $(\mathrm{Zr}, \mathrm{Ti}, \mathrm{La}, \mathrm{Pr}$, and $\mathrm{Ce})$ possess anomalous energy pathways within the basal plane (i.e., $\perp$ the $c$-axis). Figure 10 shows that hcp $\mathrm{Zr}, \mathrm{Ti}$, and La have two TS structures with equivalent energy, and the energy pathways of hcp Ce and Pr decrease firstly and then increase. The anomalous energy pathway of hcp Ti (also true for hcp Zr) was thought to be due to the presence of the bcc phase at high temperatures [8]. Except for these five elements in the hcp structure, all the other elements having bcc, fcc, and hcp structures show the "normal" bell-shaped energy pathway of vacancy migration, including hep $\mathrm{Hf}$ albeit $\mathrm{Ti}, \mathrm{Zr}$, and Hf are in the same family. It is shown that bcc Hf is absent at high temperatures [69], and this observation strengthens the hypothesis about the anomalous energy pathway of vacancy migration in the basal plane of hcp Ti [8]. Note that only three, rather than five, images were used herein for cubic structures. Anomalous energy pathways may be found in pure elements with bcc and fcc structures when more images are employed.

\subsection{Vacancy activation energy and self-diffusion coefficient}

Based on the vacancy formation energy $\left(H_{\mathrm{Va}}^{\mathrm{F}}\right)$ and vacancy migration energy $\left(H_{\mathrm{Va}}^{\mathrm{M}}\right)$, the vacancy activation energy $\left(H_{\mathrm{Va}}^{\mathrm{Q}}\right)$ can be determined, see Eq. (3). Starting from the Gibbs energies (or Helmholtz energies due to zero external pressure used in the present work) of the PS, IS, and TS structures, the vacancy-mediated self-diffusion coefficient $D_{\mathrm{Va}}$ at finite temperatures can be calculated (see Section 2). Table 5 summarizes the fitted Arrhenius parameters (see Eq. (2)) of $H_{\mathrm{Va}}^{\mathrm{Q}}$ and $A_{\mathrm{Va}}^{\mathrm{D}}$ for the stable and metastabe pure elements having bcc, fcc, and hcp structures. A 
complete list of experimental data is shown in Supplemental Materials. Similar to experiments [3] and the present vacancy concentration, $H_{\mathrm{Va}}^{\mathrm{Q}}$ and $A_{\mathrm{Va}}^{\mathrm{D}}$ are fitted in the temperature range of $0.7 T_{\mathrm{m}}$ - $T_{\mathrm{m}}$. Figure 11 illustrates a comparison of $H_{\mathrm{Va}}^{\mathrm{Q}}$ values from experiments and calculations, showing an excellent agreement with experimental measurements and indicating that the measured values of $H_{\mathrm{Va}}^{\mathrm{F}}$ (Figure 2) and $H_{\mathrm{Va}}^{\mathrm{M}}$ (Figure 6) are less accurate. In fact, some of the experimental values of $H_{\mathrm{Va}}^{\mathrm{M}}$ were indirectly estimated from $H_{\mathrm{Va}}^{\mathrm{Q}}$ and $H_{\mathrm{Va}}^{\mathrm{F}}$ [6], see the "estd" values in Supplemental Materials, such as in bcc V and bcc Nb. Similar to the vacancy formation energy $H_{\mathrm{Va}}^{\mathrm{F}}$, calculated $H_{\mathrm{Va}}^{\mathrm{Q}}$ at $0 \mathrm{~K}$ agree well with the fitted $H_{\mathrm{Va}}^{\mathrm{Q}}$ from the Arrhenius equation using data at high temperatures, see Supplemental Figure S5.

Vacancy activation energy $\left(H_{\mathrm{Va}}^{\mathrm{Q}}\right)$ is closely related to atomic bonding strength, and can be understood using data such as the melting temperature [3] and bulk modulus (see below). Figure 12 illustrates the $H_{\mathrm{Va}}^{\mathrm{Q}}$ values of pure elements having bcc, fcc, and hcp structures with respect to the melting temperature $T_{\mathrm{m}}$ and the proposed relationship in the present work,

$$
H_{\mathrm{Va}}^{\mathrm{Q}}=\frac{1}{6} B_{0} V_{0}
$$

where $B_{0}$ and $V_{0}$ are equilibrium bulk modulus and volume, respectively, as mentioned above. Eq. (17) indicates that the density of vacancy activation energy $\left(H_{\mathrm{Va}}^{\mathrm{Q}} / V_{0}\right)$ is a direct measure of bulk modulus $\left(B_{0} / 6\right)$. Figure 12 (a) shows a good linear relationship between $H_{\mathrm{Va}}^{\mathrm{Q}}$ and $T_{\mathrm{m}}$, agreeing with the previous finding [3], since $T_{\mathrm{m}}$ is also a measure of atomic bonding strength. The estimated $H_{\mathrm{Va}}^{\mathrm{Q}}$ values from $T_{\mathrm{m}}$ in Figure 12 (a) are based on a linear fitting between experimental $H_{\mathrm{Va}}^{\mathrm{Q}}$ values (see Tables 1-4 and Eq. (3)) and experimental $T_{\mathrm{m}}$ values (see the Supplemental Excel file), 


$$
H_{\mathrm{Va}}^{\mathrm{Q}}=\kappa T_{\mathrm{m}}
$$

where the fitting parameter $\kappa=0.001573 \mathrm{eV} / \mathrm{K}$ and the fitting goodness $\mathrm{R}^{2}=0.925$, indicating a good linear regression. Furthermore, $H_{\mathrm{Va}}^{\mathrm{Q}}$ can be roughly estimated using the easily obtained $B_{0}$ and $V_{0}$ via Eq. (17). Figure 12 shows that Eq. (17) is acceptable for most pure elements in terms of both the calculated and experimental $H_{\mathrm{Va}}^{\mathrm{Q}}, B_{0}$, and $V_{0}$, with large exceptions being for Au and Pt (as well as Ir and Th). The highest $H_{\mathrm{Va}}^{\mathrm{Q}}$ value is for hcp Os, since it possesses the highest bulk modulus among all pure elements [36], see Eq. (17) for the reason. It is further observed that the trend of bulk modulus [36] is similar to the trend of $H_{\mathrm{Va}}^{\mathrm{Q}}$ for pure elements on the periodic table. Concerning these quantitative relationships with $H_{\mathrm{Va}}^{\mathrm{Q}}$, the more accurate one is from $T_{\mathrm{m}}$, see Eq. (18), with the average error being $0.28 \mathrm{eV}$ as shown in Figure 12 (a). The less accurate one is from bulk modulus, see Eq. (17), with the average errors being $0.65 \mathrm{eV}$ and $0.74 \mathrm{eV}$ as shown in Figure 12 (b) and (c), respectively.

In comparison to the relatively good predictions of enthalpies $\left(H_{\mathrm{Va}}^{\mathrm{Q}}, H_{\mathrm{Va}}^{\mathrm{F}}\right.$, and $\left.H_{\mathrm{Va}}^{\mathrm{M}}\right)$, the entropyrelated frequency factor $A_{\mathrm{Va}}^{\mathrm{D}}$ from calculations shows little to no correlation with experiments, see Figure 13, as well as the data in Table 5 and Supplemental Materials. Figure 13 shows that the largest deviations between the calculated and experimental $A_{\mathrm{Va}}^{\mathrm{D}}$ values are for $\mathrm{Ag}, \mathrm{Au}, \mathrm{Ir}, \mathrm{Tl}$, $\mathrm{Pd}, \mathrm{Pt}$, and $\mathrm{Zn}$. It should be mentioned that only a few $A_{\mathrm{Va}}^{\mathrm{D}}$ measurements are available in the literature in comparison with the measured $H_{\mathrm{Va}}^{\mathrm{Q}}$, see Supplemental Materials; and the experimental $A_{\mathrm{Va}}^{\mathrm{D}}$ values contain considerable errors (compared to $H_{\mathrm{Va}}^{\mathrm{Q}}$ ) due to measurements performed at high temperatures and the purity of samples. For the example, in hcp Ti the measured $A_{\mathrm{Va}}^{\mathrm{D}}$ values vary from $1.7 \times 10^{-4}$ to $13.5 \mathrm{~cm}^{2} \mathrm{~s}^{-1}$ [8]. In addition, the omission of the 
anharmonic effect in the present work accounts for discrepancies in the calculated entropyrelated $A_{\mathrm{Va}}^{\mathrm{D}}$ (Figure 13) and $S_{\mathrm{Va}}^{\mathrm{F}}$ (see Figure 5), see the discussion at the end of Section 3.2 and the anharmonic study for fcc metals by Glensk et al. [4, 22]. Interestingly, it is found that the predicted $A_{\mathrm{Va}}^{\mathrm{D}}$ values for alkali metals $(\mathrm{Li}, \mathrm{Na}, \mathrm{K}$, and $\mathrm{Rb})$ agree very well with experimental data, due to their low melting points and to the decreased significance of the anharmonic effects.

By examining again the Arrhenius equation of Eq. (2), the present work indicates that the linear plot of " $\log \left(D_{\mathrm{Va}}\right)$ versus $1 / T$ " has a more accurate slope and less accurate intersect, since the enthalpy $\left(H_{\mathrm{Va}}^{\mathrm{Q}}\right)$ is relatively easy to obtain from experiments and calculations in comparison with the determination of the entropy-related term $\left(A_{\mathrm{Va}}^{\mathrm{D}}\right)$. It is believed that first-principles calculations using even a normal X-C functional of PBEsol and a quasiharmonic Debye model could satisfactorily account for both the enthalpy and entropy-related terms for most pure elements, with the worst predictions being for such elements as $\mathrm{Ag}, \mathrm{Au}, \mathrm{Pd}$, and $\mathrm{Pt}$ in the fcc structure.

It should be remarked that a standard first-principles study has been performed in the present work for pure elements. Advanced methods, which could lead to more accurate diffusion results, are ignored, for example, (i) the strong correlation using the Hubbard $U$ correction for $f$-electron elements [70], (ii) the anharmonic contribution to thermodynamics using the local anharmonic approximation [22], and (iii) different magnetic configurations for magnetic elements. Attention should be paid to these limitations when using the present results.

\section{Conclusions}


As an effort for computational and data-driven development and understanding of materials for the Materials Genome Initiative, a systematic investigation of the far-from-complete diffusion properties has been performed for 82 pure elements in the bcc, fcc, and hcp structures by means of a comprehensive first-principles study. The present work provides new data, new understandings, and examinations of the X-C functionals for pure elements. Here, we report a compilation of data for pure elements including vacancy formation energies $\left(H_{\mathrm{Va}}^{\mathrm{F}}\right)$, vacancy migration energies $\left(H_{\mathrm{Va}}^{\mathrm{M}}\right)$, vacancy activation energies $\left(H_{\mathrm{Va}}^{\mathrm{Q}}\right)$, vacancy concentrations $\left(C_{\mathrm{Va}}\right)$, and vacancy-mediated self-diffusion coefficients $\left(D_{\mathrm{Va}}\right)$ as a function of temperature. Specifically, the present work assesses the capability of first-principles calculations by examining four $\mathrm{X}-\mathrm{C}$ functionals (LDA, PW91, PBE, and PBEsol), equilibrium properties (such as the bulk modulus $B_{0}$ and volume $V_{0}$ from the $E-V$ equation of state), and $H_{\mathrm{Va}}^{\mathrm{F}}$. It is suggested that PBEsol is a better X-C functional to account for the enthalpy and even entropy-related terms in describing diffusivity (see the Arrhenius equation of Eqs. (1) and (2)) for most pure elements. In addition, vacancy migration energy and transition state structures are obtained using the climbing image nudged elastic band method.

Examination of the calculated quantities as well as experimental data indicates that (i) the Debye temperature, used to predict vibrational contribution to thermodynamic properties, can be predicted well from elastic constants and equilibrium properties from equations of state; (ii) enthalpies $\left(H_{\mathrm{Va}}^{\mathrm{F}}, H_{\mathrm{Va}}^{\mathrm{M}}\right.$, and $\left.H_{\mathrm{Va}}^{\mathrm{Q}}\right)$ obtained from first-principles calculations at $0 \mathrm{~K}$ agree well with the fitted results from Arrhenius equations; and the predicted enthalpies are better than the entropy-related pre-exponential factors $\left(A_{\mathrm{Va}}^{\mathrm{C}}\right.$ and $A_{\mathrm{Va}}^{\mathrm{D}}$ in the Arrhenius equation); (iii) empirical models used to predict and understand $H_{\mathrm{Va}}^{\mathrm{F}}$ from cohesive energy and especially from shear 
modulus are less accurate; (iv) the process of vacancy migration can be understood from the redistribution of differential charge density, and $H_{\mathrm{Va}}^{\mathrm{Q}}$ can be understood from interatomic bonding strength and can be predicted well from the melting point and a new relationship proposed in the present work $\left(H_{\mathrm{Va}}^{\mathrm{Q}}=B_{0} V_{0} / 6\right)$; (v) anomalous energy pathways of vacancy migration - beyond the bell-shape profile - are found for the elements $\mathrm{Ce}, \mathrm{La}, \mathrm{Pr}, \mathrm{Ti}$, and $\mathrm{Zr}$ in the hcp structure within the basal plane; and (vi) computed quantities such as $C_{\mathrm{Va}}, D_{\mathrm{Va}}, H_{\mathrm{Va}}^{\mathrm{F}}, H_{\mathrm{Va}}^{\mathrm{M}}$, and $H_{\mathrm{Va}}^{\mathrm{Q}}$ are in favorable accord with available experiments for most elements such as alkali metals ( $\mathrm{Li}, \mathrm{Na}, \mathrm{K}$, and $\mathrm{Rb}$ ), but discrepancies in predictions can be found for entropy-related properties (e.g. $A_{\mathrm{Va}}^{\mathrm{C}}$ and $A_{\mathrm{Va}}^{\mathrm{D}}$ ), which may be due to the selected $\mathrm{X}-\mathrm{C}$ functional, the ignored anharmonic effect, and large experimental uncertainty. In addition to the equations of state, diffusion-related properties, and a new understanding of diffusivity, the present work provides a benchmark of first-principles calculations and a foundational dataset for the Materials Genome Initiative.

\section{Acknowledgements}

This work was financially supported by National Science Foundation (NSF) with Grant Nos. CMMI-1333999, CHE-1230924, DMR-1310289, and DMR-1006557. First-principles calculations were carried out partially on the LION clusters at the Pennsylvania State University, partially on the resources of NERSC supported by the Office of Science of the U.S. Department of Energy under contract No. DE-AC02-05CH11231, and partially on the resources of XSEDE supported by NSF with Grant No. ACI-1053575. We also would like to thank partial firstprinciples calculations done by the previous group members of Fang Cheng, Lei Zhang, Neal Kelly, and Hongwei Yang. 


\section{References}

[1] H. Mehrer, Diffusion in solids: Fundamentals, methods, materials, diffusion-controlled processes, Springer-Verlag, Berlin, 2007.

[2] S.L. Shang, H.Z. Fang, J. Wang, C.P. Guo, Y. Wang, P.D. Jablonski, Y. Du, Z.K. Liu, Vacancy mechanism of oxygen diffusivity in bcc Fe: A first-principles study, Corros. Sci. 83 (2014) 94-102.

[3] G. Neumann, C. Tuijn, Self-diffusion and Impurity Diffusion in Pure Metals: Handbook of Experimental Data, Elsevier, Amsterdam, 2009.

[4] A. Glensk, B. Grabowski, T. Hickel, J. Neugebauer, Breakdown of the Arrhenius law in describing vacancy formation energies: The importance of local anharmonicity revealed by ab initio thermodynamics, Phys. Rev. X 4 (2014) 011018.

[5] E.A. Brandes, G.B. Brook, Smithells Metals Reference Book, seventh ed., ButterworthHeinemann, Oxford, 1992.

[6] P. Ehrhart, P. Jung, H. Schultz, H. Ullmaier, Atomic Defects in Metals, in: Landolt-Börnstein, New Series, Group III, Vol. 25. Springer-Verlag, Berlin, 1991, pp.

[7] R. Nazarov, T. Hickel, J. Neugebauer, Vacancy formation energies in fcc metals: Influence of exchange-correlation functionals and correction schemes, Phys. Rev. B 85 (2012) 144118.

[8] S.L. Shang, L.G. Hector, Y. Wang, Z.K. Liu, Anomalous energy pathway of vacancy migration and self-diffusion in hcp Ti, Phys. Rev. B 83 (2011) 224104.

[9] Z.K. Liu, L.Q. Chen, R. Raghavan, Q. Du, J.O. Sofo, S.A. Langer, C. Wolverton, An integrated framework for multi-scale materials simulation and design, J. Comput. -Aided Mater. Design 11 (2004) 183-199.

[10] G.B. Olson, Computational design of hierarchically structured materials, Science 277 (1997) 1237-1242.

[11] J.P. Perdew, A. Zunger, Self-interaction correction to density-functional approximations for many-electron systems, Phys. Rev. B 23 (1981) 5048-5079.

[12] J.P. Perdew, J.A. Chevary, S.H. Vosko, K.A. Jackson, M.R. Pederson, D.J. Singh, C. Fiolhais, Atoms, molecules, solids, and surfaces - Applications of the generalized gradient approximation for exchange and correlation, Phys. Rev. B 46 (1992) 6671-6687.

[13] J.P. Perdew, Y. Wang, Accurate and simple analytic representation of the electron-gas correlation-energy, Phys. Rev. B 45 (1992) 13244-13249. 
[14] J.P. Perdew, K. Burke, M. Ernzerhof, Generalized gradient approximation made simple, Phys. Rev. Lett. 77 (1996) 3865-3868.

[15] R. Armiento, A.E. Mattsson, Functional designed to include surface effects in selfconsistent density functional theory, Phys. Rev. B 72 (2005) 085108.

[16] B. Medasani, M. Haranczyk, A. Canning, M. Asta, Vacancy formation energies in metals: A comparison of MetaGGA with LDA and GGA exchange-correlation functionals, Comput. Mater. Sci. 101 (2015) 96-107.

[17] J.P. Perdew, A. Ruzsinszky, G.I. Csonka, O.A. Vydrov, G.E. Scuseria, L.A. Constantin, X. Zhou, K. Burke, Restoring the density-gradient expansion for exchange in solids and surfaces, Phys. Rev. Lett. 100 (2008) 136406.

[18] J. Sun, M. Marsman, G.I. Csonka, A. Ruzsinszky, P. Hao, Y.-S. Kim, G. Kresse, J.P. Perdew, Self-consistent meta-generalized gradient approximation within the projectoraugmented-wave method, Phys. Rev. B 84 (2011) 035117.

[19] T. Angsten, T. Mayeshiba, H. Wu, D. Morgan, Elemental vacancy diffusion database from high-throughput first-principles calculations for fcc and hcp structures, New J. Phys. 16 (2014) 015018.

[20] W.W. Xing, P.T. Liu, X.Y. Cheng, H.Y. Niu, H. Ma, D.Z. Li, Y.Y. Li, X.Q. Chen, Vacancy formation enthalpy of filled d-band noble metals by hybrid functionals, Phys. Rev. B 90 (2014) 144105.

[21] C. Freysoldt, B. Grabowski, T. Hickel, J. Neugebauer, G. Kresse, A. Janotti, C.G. Van de Walle, First-principles calculations for point defects in solids, Rev. Mod. Phys. 86 (2014) 253305.

[22] A. Glensk, B. Grabowski, T. Hickel, J. Neugebauer, Understanding anharmonicity in fcc materials: From its origin to ab initio strategies beyond the quasiharmonic approximation, Phys. Rev. Lett. 114 (2015) 195901.

[23] B. Grabowski, T. Hickel, J. Neugebauer, Formation energies of point defects at finite temperatures, Phys. Status Solidi B 248 (2011) 1295-1308.

[24] G. Henkelman, B.P. Uberuaga, H. Jonsson, A climbing image nudged elastic band method for finding saddle points and minimum energy paths, J. Chem. Phys. 113 (2000) 9901-9904. [25] M. Mantina, Y. Wang, R. Arroyave, L.Q. Chen, Z.K. Liu, C. Wolverton, First-principles calculation of self-diffusion coefficients, Phys. Rev. Lett. 100 (2008) 215901. 
[26] C.Z. Hargather, S.-L. Shang, Z.-K. Liu, Y. Du, A first-principles study of self-diffusion coefficients of fcc Ni, Comput. Mater. Sci. 86 (2014) 17-23.

[27] H.Z. Fang, S.L. Shang, Y. Wang, Z.K. Liu, D. Alfonso, D.E. Alman, Y.K. Shin, C.Y. Zou, A.C.T. van Duin, K. Lei, G.F. Wang, First-principles studies on vacancy-modified interstitial diffusion mechanism of oxygen in nickel, associated with large-scale atomic simulation techniques, J. Appl. Phys. 115 (2014) 043501.

[28] M. Mantina, S.L. Shang, Y. Wang, L.Q. Chen, Z.K. Liu, 3d transition metal impurities in aluminum: A first-principles study, Phys. Rev. B 80 (2009) 184111.

[29] M. Mantina, Y. Wang, L.Q. Chen, Z.K. Liu, C. Wolverton, First principles impurity diffusion coefficients, Acta Mater. 57 (2009) 4102-4108.

[30] M. Mantina, L.Q. Chen, Z.K. Liu, Predicting diffusion coefficients from first-principles via Eyring's reaction rate theory, Def. Diff. Forum 294 (2009) 1-13.

[31] S. Ganeshan, L.G. Hector, Z.K. Liu, First-principles calculations of impurity diffusion coefficients in dilute Mg alloys using the 8-frequency model, Acta Mater. 59 (2011) 3214-3228.

[32] S. Ganeshan, L.G. Hector, Z.K. Liu, First-principles study of self-diffusion in hcp Mg and Zn, Comput. Mater. Sci. 50 (2010) 301-307.

[33] M. Mantina, Y. Wang, R. Arroyave, S.L. Shang, L.Q. Chen, Z.K. Liu, A first-principles approach to transition states of diffusion, J. Phys.-Condens. Matter 24 (2012) 305402.

[34] B.-C. Zhou, S.-L. Shang, Y. Wang, Z.-K. Liu, Diffusion coefficients of alloying elements in dilute Mg alloys: A comprehensive first-principles study, Acta Mater. 103 (2016) 573-586.

[35] S.L. Shang, Y. Wang, D. Kim, Z.K. Liu, First-principles thermodynamics from phonon and Debye model: Application to $\mathrm{Ni}$ and $\mathrm{Ni}_{3} \mathrm{Al}$, Comput. Mater. Sci. 47 (2010) 1040-1048.

[36] S.L. Shang, A. Saengdeejing, Z.G. Mei, D.E. Kim, H. Zhang, S. Ganeshan, Y. Wang, Z.K. Liu, First-principles calculations of pure elements: Equations of state and elastic stiffness constants, Comput. Mater. Sci. 48 (2010) 813-826.

[37] Z.-K. Liu, First-principles calculations and CALPHAD modeling of thermodynamics, J. Phase Equilib. Diff. 30 (2009) 517-534.

[38] S. Shang, Y. Wang, Y. Du, M.A. Tschopp, Z.-K. Liu, Integrating computational modeling and first-principles calculations to predict stacking fault energy of dilute multicomponent $\mathrm{Ni}$ base alloys, Comput. Mater. Sci. 91 (2014) 50-55. 
[39] N. Saunders, A.P. Miodownik, CALPHAD (Calculation of Phase Diagrams): A Comprehensive Guide, Elsevier Science, New York, 1998.

[40] H. Eyring, The activated complex in chemical reactions, J. Chem. Phys. 3 (1935) 107-115.

[41] N.L. Peterson, Self-diffusion in pure metals, J. Nucl. Mater. 69-70 (1978) 3-37.

[42] J.G. Mullen, Effect of Bardeen-Herring correlation on vacancy diffusion in anisotropic crystals, Phys. Rev. 124 (1961) 1723-1730.

[43] E. Wimmer, W. Wolf, J. Sticht, P. Saxe, C.B. Geller, R. Najafabadi, G.A. Young, Temperature-dependent diffusion coefficients from ab initio computations: Hydrogen, deuterium, and tritium in nickel, Phys. Rev. B 77 (2008) 134305.

[44] Y. Wang, Z.K. Liu, L.Q. Chen, Thermodynamic properties of $\mathrm{Al}, \mathrm{Ni}, \mathrm{NiAl}$, and $\mathrm{Ni}_{3} \mathrm{Al}$ from first-principles calculations, Acta Mater. 52 (2004) 2665-2671.

[45] S.L. Shang, Y. Wang, P.W. Guan, W.Y. Wang, H.Z. Fang, T. Anderson, Z.-K. Liu, Insight into structural, elastic, phonon, and thermodynamic properties of alpha-sulfur and energy-related sulfides: a comprehensive first-principles study, J. Mater. Chem. A 3 (2015) 8002-8014.

[46] V.L. Moruzzi, J.F. Janak, K. Schwarz, Calculated thermal properties of metals, Phys. Rev. B 37 (1988) 790-799.

[47] X.L. Liu, B.K. VanLeeuwen, S.-L. Shang, Y. Du, Z.-K. Liu, On the scaling factor in DebyeGruneisen model: A case study of the Mg-Zn binary system, Comput. Mater. Sci. 98 (2015) 3441.

[48] G. Kresse, J. Furthmuller, Efficient iterative schemes for ab initio total-energy calculations using a plane-wave basis set, Phys. Rev. B 54 (1996) 11169-11186.

[49] G. Kresse, J. Furthmuller, Efficiency of ab-initio total energy calculations for metals and semiconductors using a plane-wave basis set, Comput. Mater. Sci. 6 (1996) 15-50.

[50] G. Kresse, D. Joubert, From ultrasoft pseudopotentials to the projector augmented-wave method, Phys. Rev. B 59 (1999) 1758-1775.

[51] M. Methfessel, A.T. Paxton, High-precision sampling for Brillouin-zone integration in metals, Phys. Rev. B 40 (1989) 3616-3621.

[52] P.E. Blöchl, O. Jepsen, O.K. Andersen, Improved tetrahedron method for Brillouin-zone integrations, Phys. Rev. B 49 (1994) 16223-16233. 
[53] Y. Wang, S. Curtarolo, C. Jiang, R. Arroyave, T. Wang, G. Ceder, L.Q. Chen, Z.K. Liu, Ab initio lattice stability in comparison with CALPHAD lattice stability, CALPHAD 28 (2004) 7990.

[54] P. Villars, L.D. Calvert, Pearson's handbook of crystallographic data for intermetallic phases, ASTM International, Newbury, OH, 1991.

[55] C. Kittel, Introduction to solid state physics, John Wiley \& Sons, Inc, Hoboken, NJ, 2005.

[56] M.I. Baskes, R.A. Johnson, Modified embedded-atom potentials for hep metals, Model. Simul. Mater. Sci. Eng. 2 (1994) 147-163.

[57] B.W. Zhang, Y.F. Ouyang, S.Z. Liao, Z.P. Jin, An analytic MEAM model for all bcc transition metals, Physica B 262 (1999) 218-225.

[58] T. Hehenkamp, W. Berger, J.E. Kluin, C. Lüdecke, J. Wolff, Equilibrium vacancy concentrations in copper investigated with the absolute technique, Phys. Rev. B 45 (1992) 19982003.

[59] G.M. Hood, Comments on positron annihilation and the vacancy properties of Mg, Phys. Rev. B 26 (1982) 1036-1037.

[60] S.L. Shang, Y. Wang, Y. Du, Z.K. Liu, Entropy favored ordering: Phase stability of $\mathrm{Ni}_{3} \mathrm{Pt}$ revisited by first-principles, Intermetallics 18 (2010) 961-964.

[61] T. Górecki, Vacancies and changes of physical properties of metals at the melting point, Z. Metallkd. 65 (1974) 426-431.

[62] A.S. Argon, Strengthening mechanisms in crystal plasticity, Oxford University Press Oxford, 2008.

[63] S. Ogata, J. Li, S. Yip, Ideal pure shear strength of aluminum and copper, Science 298 (2002) 807-811.

[64] P.N.H. Nakashima, A.E. Smith, J. Etheridge, B.C. Muddle, The bonding electron density in aluminum, Science 331 (2011) 1583-1586.

[65] S.L. Shang, D.E. Kim, C.L. Zacherl, Y. Wang, Y. Du, Z.K. Liu, Effects of alloying elements and temperature on the elastic properties of dilute Ni-base superalloys from firstprinciples calculations, J. Appl. Phys. 112 (2012) 053515.

[66] S.L. Shang, W.Y. Wang, Y. Wang, Y. Du, J.X. Zhang, A.D. Patel, Z.K. Liu, Temperaturedependent ideal strength and stacking fault energy of fcc Ni: A first-principles study of shear deformation, J. Phys.-Condens. Matter 24 (2012) 155402. 
[67] S.L. Shang, C.L. Zacherl, H.Z. Fang, Y. Wang, Y. Du, Z.K. Liu, Effects of alloying element and temperature on the stacking fault energies of dilute Ni-base superalloys, J. Phys.-Condens. Matter 24 (2012) 505403.

[68] S.L. Shang, W.Y. Wang, B.C. Zhou, Y. Wang, K.A. Darling, L.J. Kecskes, S.N. Mathaudhu, Z.K. Liu, Generalized stacking fault energy, ideal strength and twinnability of dilute Mg-based alloys: A first-principles study of shear deformation, Acta Mater. 67 (2014) 168-180.

[69] E.Y. Tonkov, E.G. Ponyatovsky, Phase transformations of elements under high pressure, CRC Press, Boca Raton, FL, 2004.

[70] Y. Wang, L.G. Hector, H. Zhang, S.L. Shang, L.Q. Chen, Z.K. Liu, Thermodynamics of the Ce $\gamma-\alpha$ transition: Density-functional study, Phys. Rev. B 78 (2008) 104113. 
FIGURES AND FIGURE CAPTIONS
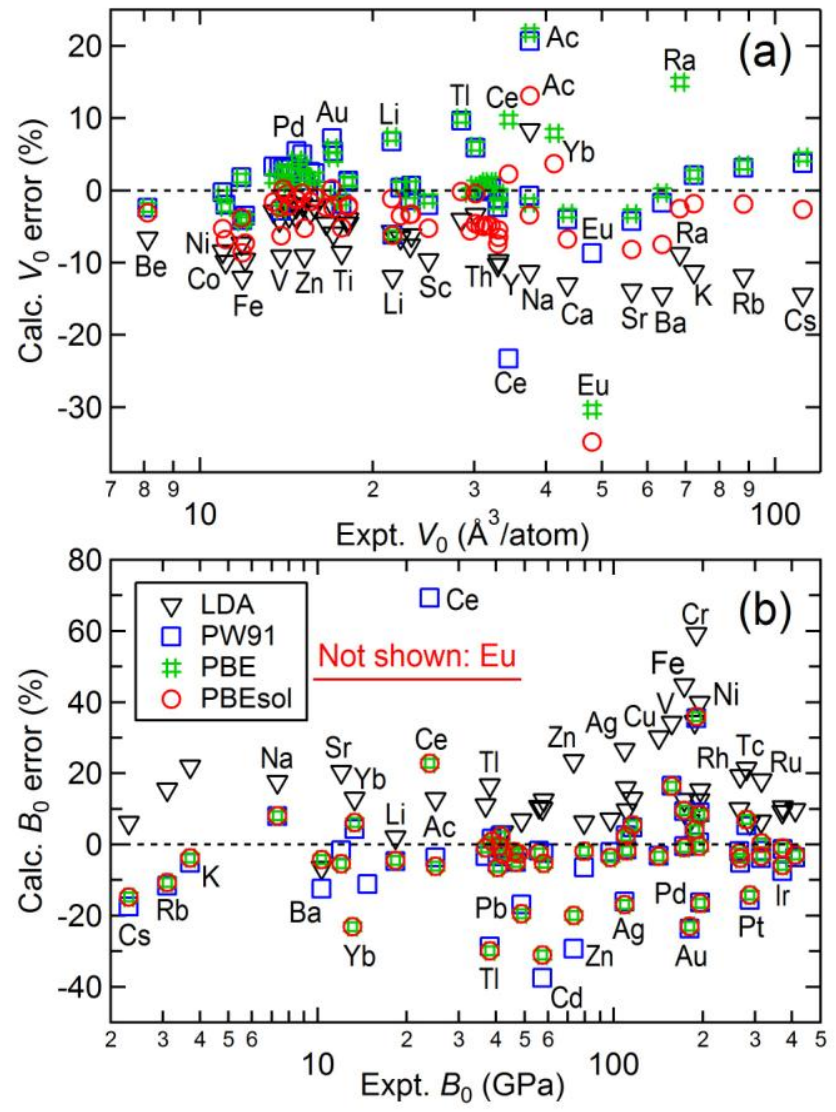

Figure 1. Errors of the calculated equilibrium volumes $V_{0}$ (a) and bulk moduli $B_{0}(\mathrm{~b})$ at $0 \mathrm{~K}$ for pure elements compared with experimental data. Here, the room temperature bcc, fcc, or hcp structure is adopted for each element (see Table 1); calculated $V_{0}$ and $B_{0}$ are determined by the $E$ $V$ EOS of Eq. (11); and all the calculated and experimental data are listed in Excel file as Supplemental Materials. The not shown data are $B_{0}$ of Eu from PBE and PBEsol, which have large errors (>100\%) with respect to experimental data. 


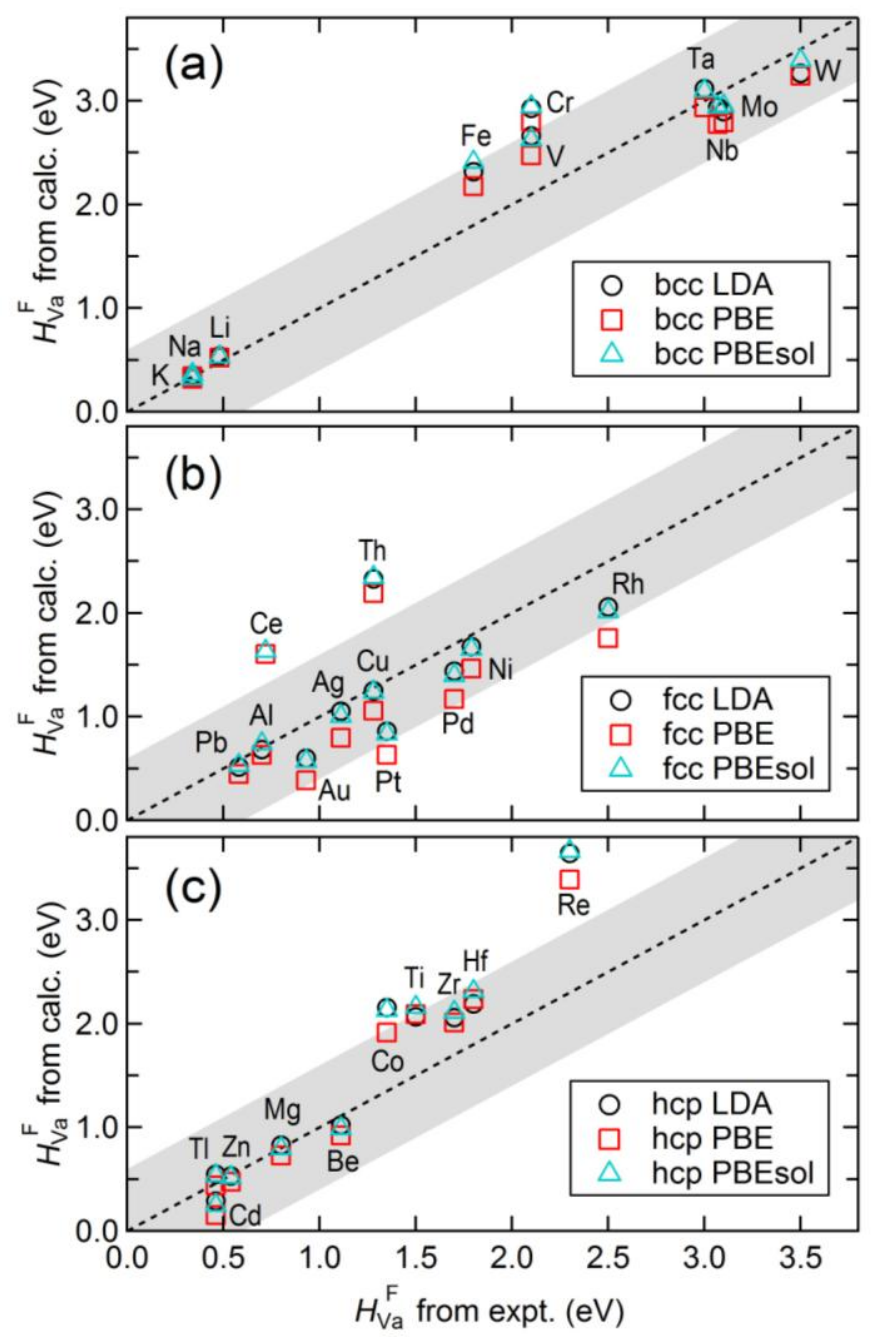

Figure 2. Comparison of vacancy formation energies $\left(H_{\mathrm{Va}}^{\mathrm{F}}\right)$ from experiments and firstprinciples calculations for pure elements in bcc (a), fcc (b), and hcp (c) structures. Calculated and experimental values are also given in Table 1, Table 2, and Table 3. Dashed lines indicate value equality and the values in shaded area (error of $\pm 0.6 \mathrm{eV}$ ) indicate a good agreement. 


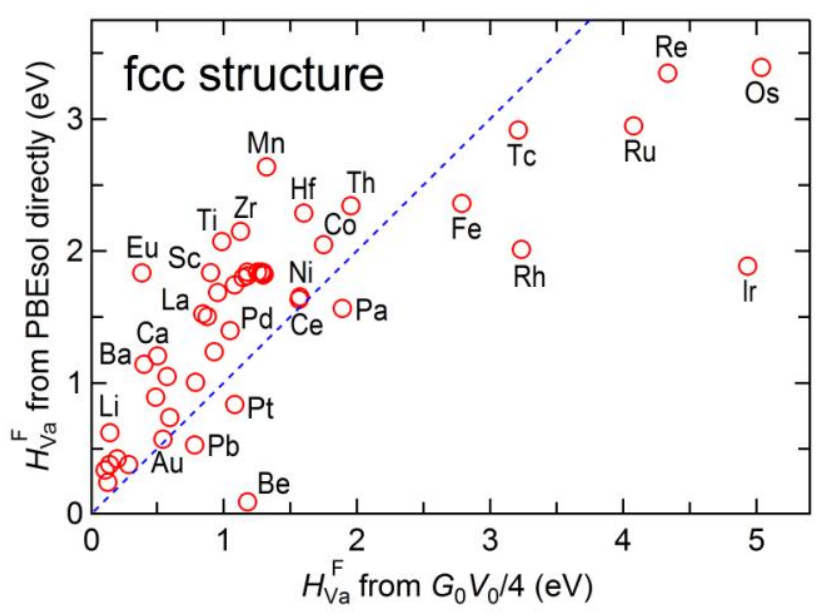

Figure 4. Comparison of vacancy formation energies $\left(H_{\mathrm{Va}}^{\mathrm{F}}\right)$ from shear modulus (see Eq. (16)) and first-principles (PBEsol) for the case of pure elements in the fcc structure. Dashed line indicates value equality and all data are listed in Table 2 and Excel file (Supplemental Materials). 

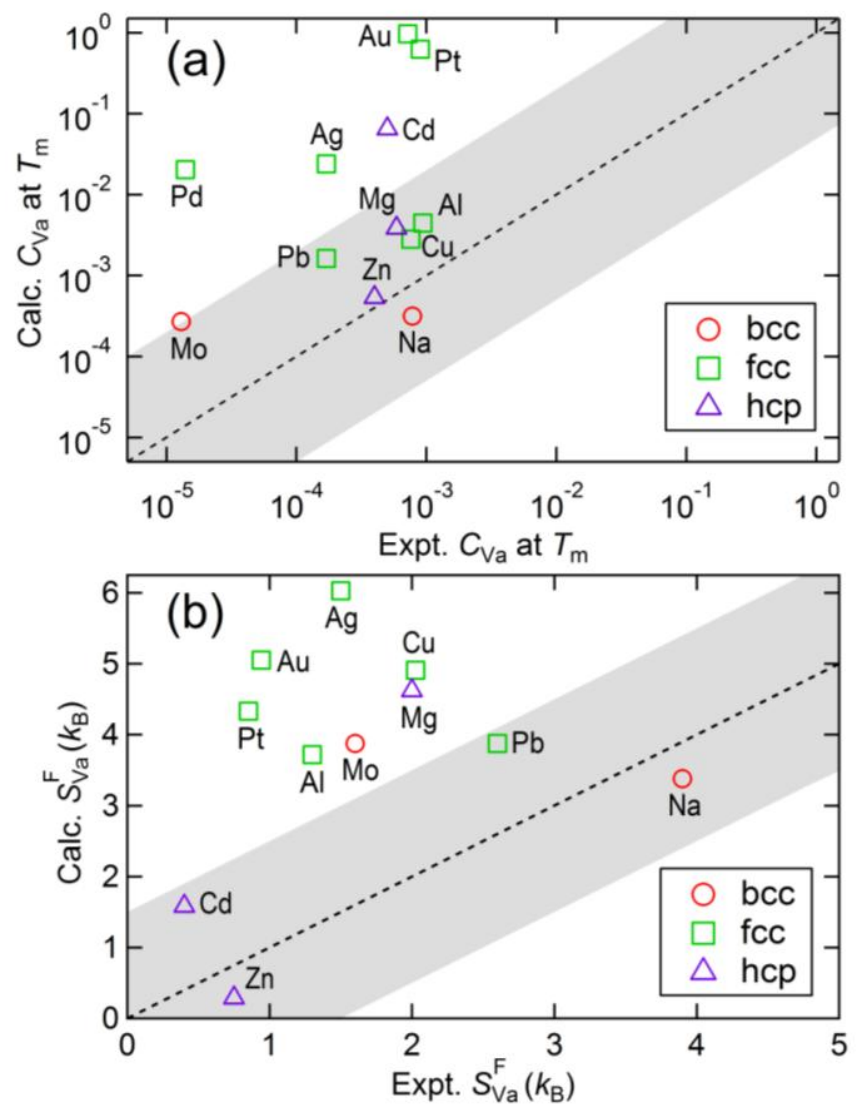

Figure 5. Comparison of calculated and experimental vacancy concentrations $\left(C_{\mathrm{Va}}\right)$ of pure elements at their melting points $\left(T_{\mathrm{m}}\right)$ (a) together with a comparison of vacancy formation entropies $\left(S_{\mathrm{Va}}^{\mathrm{F}}\right)(\mathrm{b}) . C_{\mathrm{Va}}$ is calculated by Eq. $(1)$, and $S_{\mathrm{Va}}^{\mathrm{F}}$ is estimated by $\ln \left(A_{\mathrm{Va}}^{\mathrm{D}}\right)$. All data are given in Excel file in Supplemental Materials, dashed lines indicate value equality and the data in shaded area (error of 200 times for (a) and $\pm 1.5 k_{\mathrm{B}}$ for (b)) indicate a good agreement. 


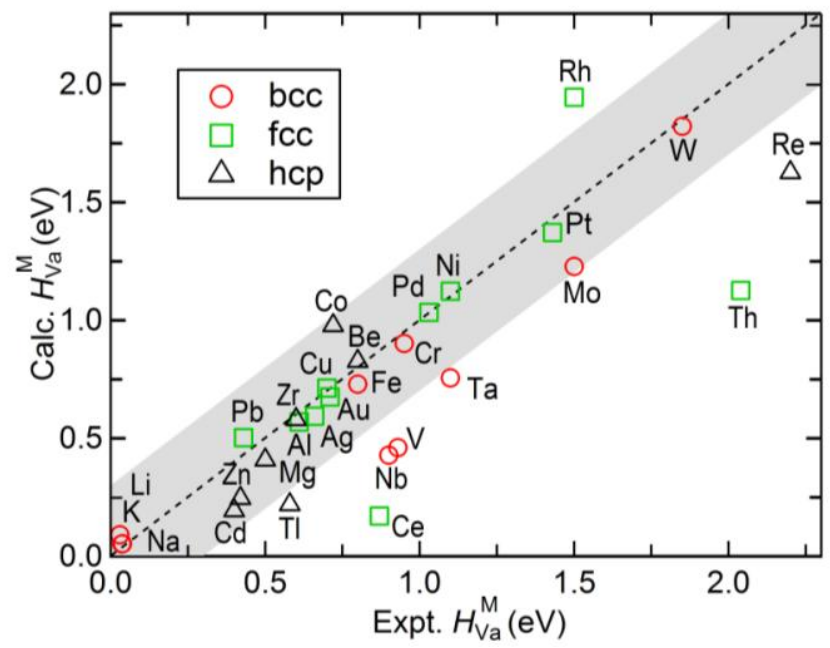

Figure 6. Comparison of calculated and experimental vacancy migration energies $\left(H_{\mathrm{Va}}^{\mathrm{M}}\right)$ of pure elements. Calculated values from PBEsol are given in Table 4 (the average one is used for hcp lattice); experimental data are average values based on data in Supplemental Materials; dashed line indicates value equality; and the values in shaded area (error of $\pm 0.3 \mathrm{eV}$ ) indicate a good agreement.

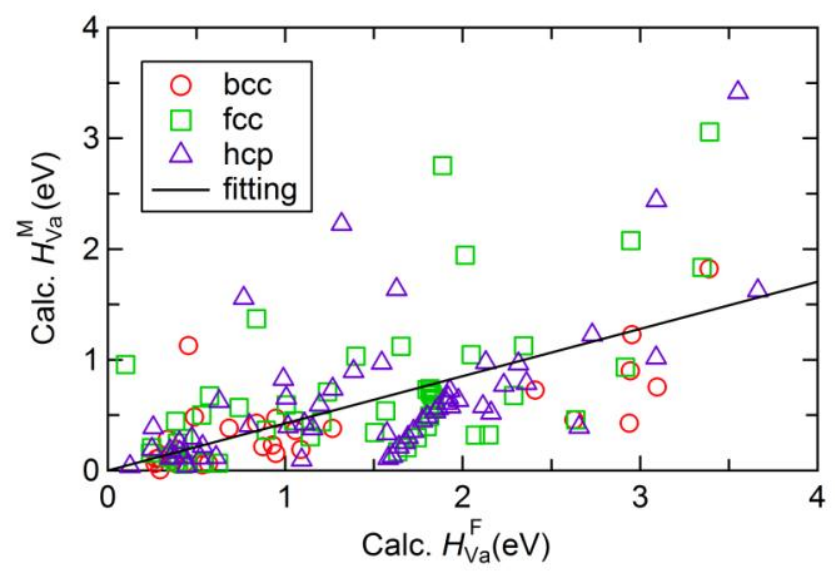

Figure 7. Comparison of calculated vacancy formation energies $\left(H_{\mathrm{Va}}^{\mathrm{F}}\right)$ and vacancy migration energies $\left(H_{\mathrm{Va}}^{\mathrm{M}}\right)$ for pure elements in bcc, fcc, and hcp structures. All data are given in Table 1, Table 2, Table 3, and Table 4; and the solid line is a linear fitting of $H_{\mathrm{Va}}^{\mathrm{M}}=0.43 H_{\mathrm{Va}}^{\mathrm{F}}$. 


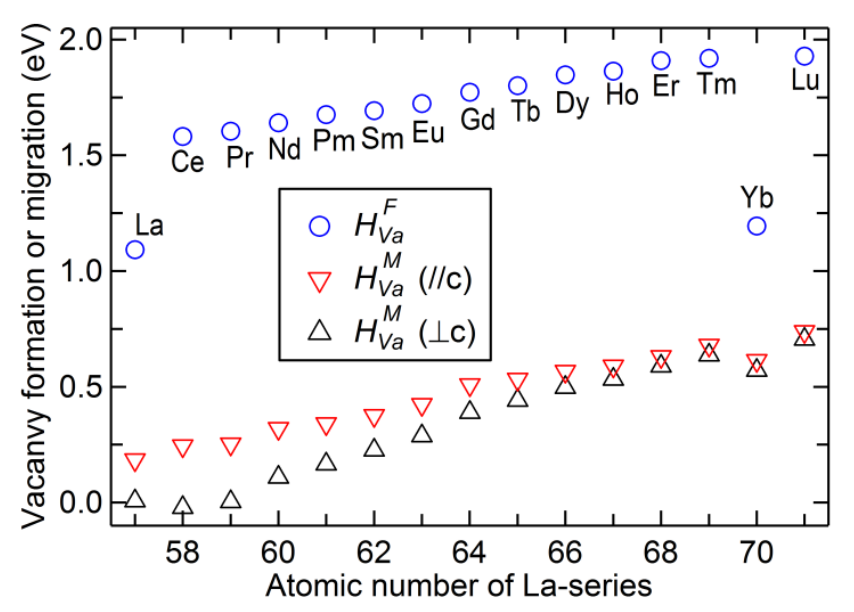

Figure 8. Calculated vacancy formation energies $\left(H_{\mathrm{Va}}^{\mathrm{F}}\right)$ and vacancy migration energies $\left(H_{\mathrm{Va}}^{\mathrm{M}}\right)$ of the La-series rare earth elements in the hcp structure and at $0 \mathrm{~K}$. All data are listed in Table 3 and Table 4. Predicted values of $\mathrm{Yb}$ (as well as La) are relatively small, implying an issue of firstprinciples calculations. 


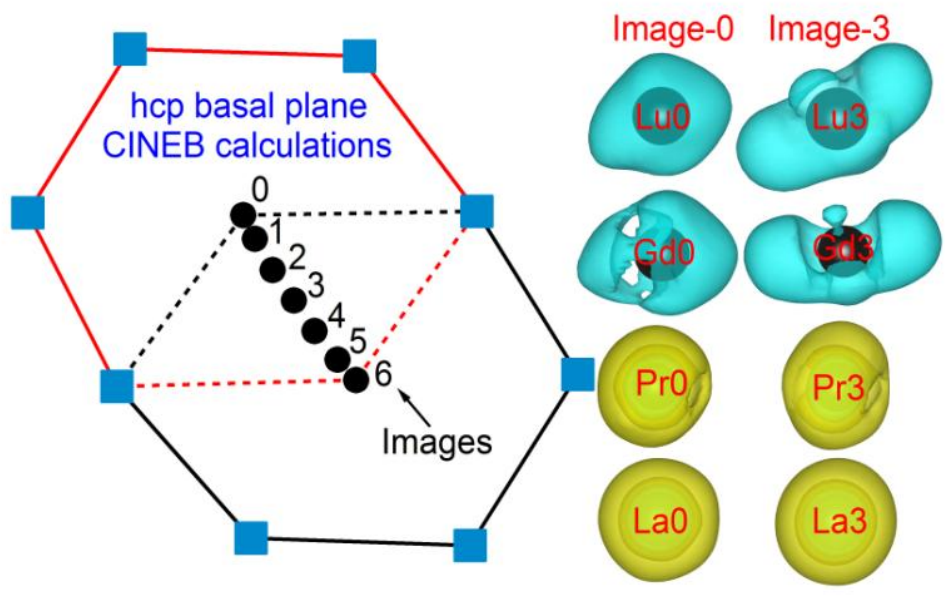

Figure 9. Atomic positions for vacancy migration within an hcp basal plane from first-principles CINEB calculations (view along the $c$-axis, left figure). The filled symbols represent atoms within the basal plane, and positions 0-6 denote the migrating atom at images 0-6, respectively. Isosurfaces of the differential charge density contours (using $0.5 \Delta \rho_{\max }$ to plot, right figure) are shown for the migrating atom (black sphere inside) at image 0 (IS structure) and image 3 (TS structure) of $\mathrm{Lu}, \mathrm{Gd}, \mathrm{Pr}$, and $\mathrm{La}$, where the light blue color represents charge loss (inside the yellow color for Pr and La) and the yellow color represents charge gain (not shown for Lu and Gd).

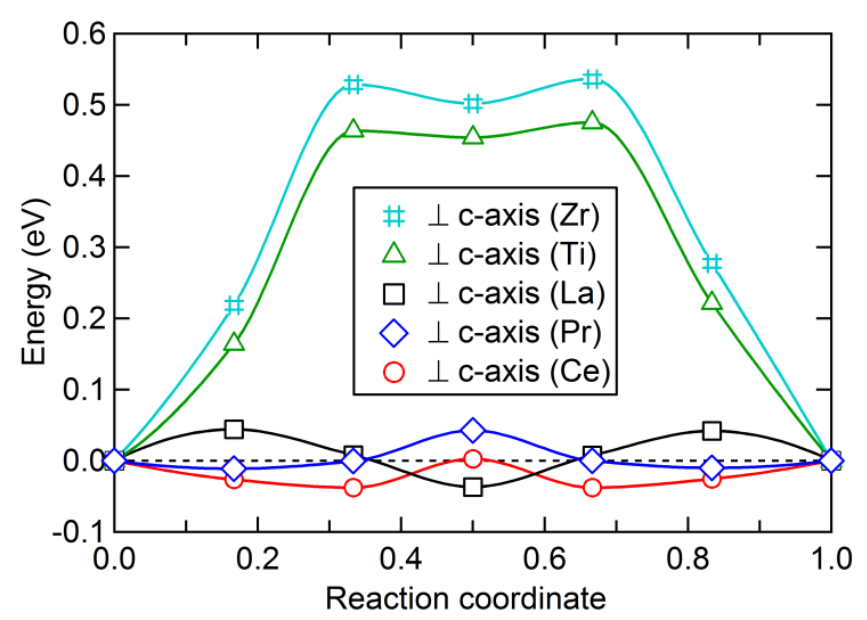

Figure 10. Anomalous energy pathways of hcp elements ( $\mathrm{Zr}, \mathrm{Ti}, \mathrm{La}, \mathrm{Pr}$, and $\mathrm{Ce}$ ) within the basal plane $(\perp$ c-axis) predicted from first-principles CINEB calculations in terms of PBEsol. The curves are fittings using the cubic spline interpolation. 

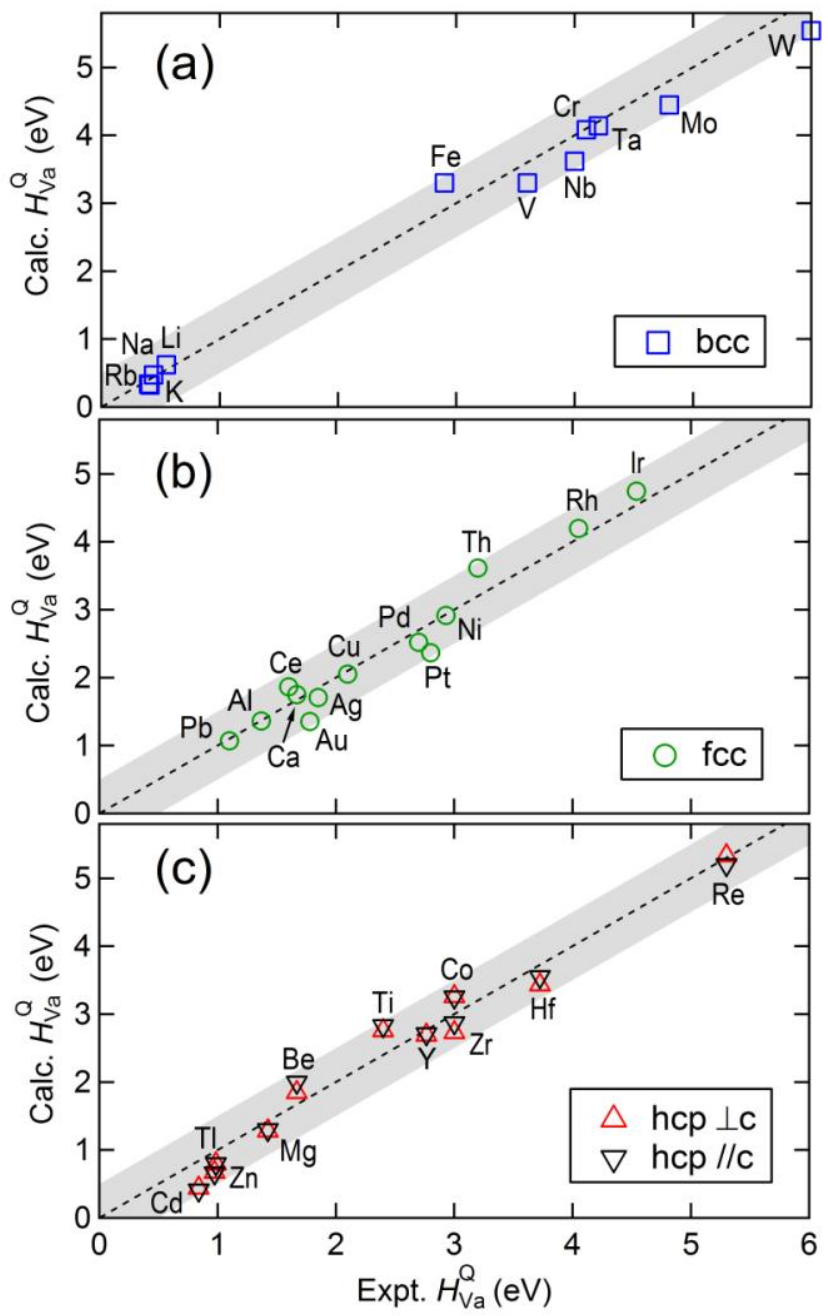

Figure 11. Calculated and experimental vacancy activation energies $\left(H_{\mathrm{Va}}^{\mathrm{Q}}\right)$ for pure elements. All data are given in Table 5 and Supplemental Materials; dashed lines indicate value equality; and the values in shaded area (error of $\pm 0.5 \mathrm{eV}$ ) indicate a good agreement. 

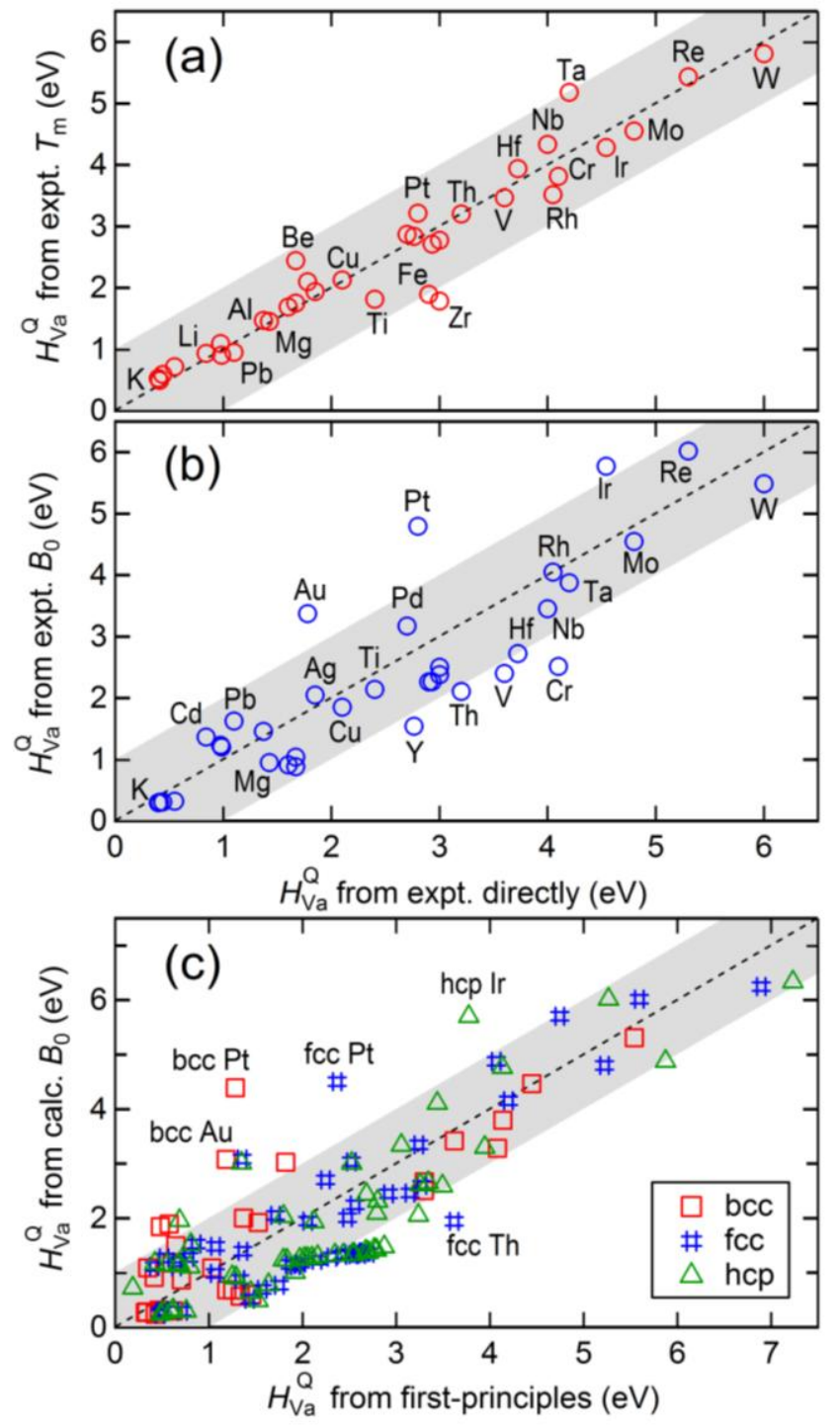

Figure 12. Comparison of vacancy activation energies $\left(H_{\mathrm{Va}}^{\mathrm{Q}}\right)$ for pure elements from firstprinciples calculations directly, from calculated and measured bulk modulus $B_{0}$ and equilibrium volume $V_{0}$ (used to estimate $H_{\mathrm{Va}}^{\mathrm{Q}}$ using Eq. (17)), and from measured melting point $T_{\mathrm{m}}$ (used to estimate $H_{\mathrm{Va}}^{\mathrm{Q}}$ using Eq. (18)). First-principles results were performed at $0 \mathrm{~K}$ in terms of PBEsol and these data are listed in Supplemental Excel file. Measured $H_{\mathrm{Va}}^{\mathrm{Q}}\left(=H_{\mathrm{Va}}^{\mathrm{F}}+H_{\mathrm{Va}}^{\mathrm{M}}\right)$ values are given in Tables 1-4, and the measured $V_{0}, B_{0}$, and $T_{\mathrm{m}}$ values are given Supplemental Excel file. Dashed lines indicate value equality; and the values in shaded area (difference of $\pm 1 \mathrm{eV}$ ) indicate a good agreement. 


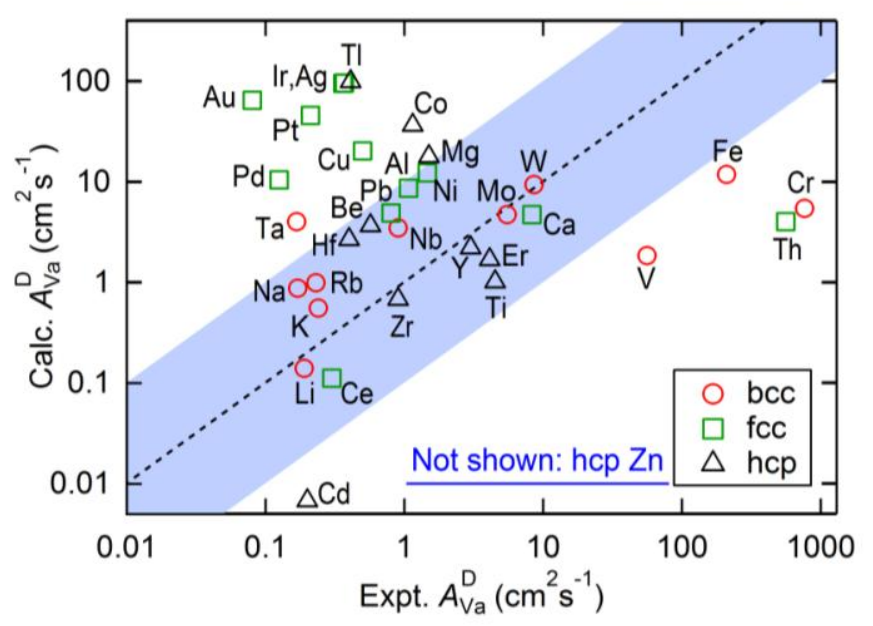

Figure 13. Comparison of calculated and experimental frequency factors for pure elements $\left(A_{\mathrm{Va}}^{\mathrm{D}}\right)$ from Arrhenius fitting. Calculated values from PBEsol are given in Table 5 (average values used for hcp lattices); experimental data are average based on data in Supplemental Materials; dashed line indicates value equality; and the values in shaded area (error of 10 times) indicate a good agreement. 
Table 1. Calculated vacancy formation energies/enthalpies at $0 \mathrm{~K}\left(H_{\mathrm{Va}}^{\mathrm{F}}, \mathrm{eV}\right)$ of bcc structure together with the presently suggested experimental data in parentheses, see Supplemental Materials for details. Note that (i) the superscript * indicates the stable or metastable structure by the predicted elastic constants [36]; (ii) \# indicates the structure with a positive $H_{\mathrm{Va}}^{\mathrm{F}}$ and a smaller energy difference between two different vacancy structures $\left(\Delta E_{\mathrm{Va}}\right.$-Va2 $<1$ meV); (iii) $\S$ indicates $\Delta E_{\mathrm{Va1}-\mathrm{Va} 2}>4 \mathrm{meV}$; (iv) $\otimes$ indicates that only vibrational contribution by Debye model is used to calculate thermodynamic properties; and (v) detailed valence states are given for each element (pv, and sv, etc).

\begin{tabular}{|c|c|c|c|c|c|c|c|c|c|c|c|c|c|c|c|c|}
\hline & & & & & & & & & & & & \multirow{2}{*}{\multicolumn{2}{|c|}{$\begin{array}{l}\text { B } \\
\text { rhomb } \\
-8.49 \\
-5.02 \\
-4.85\end{array}$}} & \multirow[b]{2}{*}{$\mathbf{N}$} & \multirow[b]{2}{*}{$\mathbf{O}$} & \multirow[b]{2}{*}{$\mathbf{F}$} \\
\hline $\begin{array}{c}\mathbf{L i}_{\mathbf{b} c \mathrm{~s}} \mathbf{*}^{* \#} \\
0.54 \\
0.52 \\
0.53 \\
(0.48)\end{array}$ & $\begin{array}{l}\mathbf{B e}^{*} \\
\text { hcp } \\
-0.74 \\
-0.82 \\
-0.75\end{array}$ & \multirow{2}{*}{\multicolumn{3}{|c|}{4}} & \multirow{2}{*}{\multicolumn{4}{|c|}{$\begin{array}{c}\text { Structure at room temperature } \\
\text { Calc. } H_{\mathrm{Va}}^{\mathrm{F}} \text { of bcc structure by LDA } \\
\text { Calc. } H_{\mathrm{Va}}^{\mathrm{F}} \text { of bcc structure by PBE } \\
\text { Calc. } H_{\mathrm{Va}}^{\mathrm{F}} \text { of bcc structure by PBEsol } \\
\text { Expt. } H_{\mathrm{Va}}^{\mathrm{F}} \text { of bcc structure if available }\end{array}$}} & & & & & & & & \\
\hline $\begin{array}{c}\text { Na_pv }{ }^{* \#} \\
\text { bcc } \\
0.35 \\
0.34 \\
0.36 \\
(0.34)\end{array}$ & $\begin{array}{c}\mathbf{M g}^{* \# \#} \\
\text { hcp } \\
0.57 \\
0.53 \\
0.57\end{array}$ & & & & & & & & & & & $\begin{array}{c}\mathbf{A l}^{\#} \\
\mathbf{f c c} \\
0.25 \\
0.23 \\
0.30\end{array}$ & $\begin{array}{c}\mathbf{S i}^{\S \otimes} \\
\text { diamond } \\
0.47 \\
0.39 \\
0.54\end{array}$ & $\begin{array}{c}\mathbf{P}^{* \S} \\
\text { complex } \\
0.47 \\
-0.05 \\
0.52\end{array}$ & $\begin{array}{c}\mathbf{S}^{\S} \\
\text { orth } \\
0.05 \\
0.34 \\
-0.09\end{array}$ & Cl \\
\hline $\begin{array}{c}\text { K_ss }{ }^{* *} \\
\text { bcc } \\
0.32 \\
0.32 \\
0.32 \\
(0.34)\end{array}$ & $\begin{array}{l}\text { Ca_pv }{ }^{\#} \\
\text { fcc } \\
0.92 \\
0.84 \\
0.87\end{array}$ & $\begin{array}{c}\text { Sc_sv } \\
\text { hcp } \\
-0.24 \\
0.47 \\
0.27\end{array}$ & $\begin{array}{c}\text { Ti_pv }^{\S} \\
\text { hcp } \\
-0.18 \\
-0.27 \\
2.82\end{array}$ & $\begin{array}{l}\mathbf{V} \_\mathbf{p v}{ }^{* \#} \\
\text { bcc } \\
2.66 \\
2.48 \\
2.63 \\
(2.1)\end{array}$ & $\begin{array}{c}\text { Cr_pv }{ }^{* \#} \\
\text { bcc } \\
2.93 \\
2.79 \\
2.94 \\
(2.1)\end{array}$ & $\begin{array}{c}\text { Mn } \\
\text { complex } \\
-1.23 \\
-0.32 \\
-0.73\end{array}$ & $\begin{array}{c}\mathbf{F e}^{* \#} \\
\mathrm{bcc} \\
2.32 \\
2.18 \\
2.41 \\
(1.8)\end{array}$ & $\begin{array}{l}\mathbf{C o}^{\# \otimes} \\
\text { hcp } \\
0.40 \\
0.64 \\
0.62\end{array}$ & $\begin{array}{c}\mathbf{N i}^{\#} \\
\text { fcc } \\
1.21 \\
0.98 \\
1.11\end{array}$ & $\begin{array}{l}\mathbf{C u}^{\#} \\
\text { Fcc } \\
1.08 \\
0.90 \\
1.06\end{array}$ & $\begin{array}{c}\text { Zn } \\
\text { hcp } \\
-0.37 \\
-0.26 \\
-0.30\end{array}$ & $\begin{array}{c}\text { Ga_dd }^{\#} \\
\text { complex } \\
0.21 \\
0.23 \\
0.27\end{array}$ & $\begin{array}{c}\text { Ge_d } \\
\text { diamond } \\
-0.62 \\
-0.72 \\
-0.46\end{array}$ & $\begin{array}{c}\mathbf{A s}^{*} \\
\text { rhomb } \\
-0.10 \\
-0.30 \\
0.02\end{array}$ & $\begin{array}{c}\mathbf{S e} \\
\text { rhomb } \\
-2.41 \\
0.94 \\
-2.64\end{array}$ & $\begin{array}{c}\mathbf{B r} \\
- \\
-0.21 \\
-0.31 \\
-0.25\end{array}$ \\
\hline $\begin{array}{c}\mathbf{R b} \_\mathbf{s v}^{* * \#} \\
\text { bcc } \\
0.29 \\
0.28 \\
0.29\end{array}$ & $\begin{array}{c}\mathbf{S r}_{-} \mathbf{s v}^{* \#} \\
\text { fcc } \\
1.01 \\
0.85 \\
0.93\end{array}$ & $\begin{array}{c}\text { Y_sv } \\
\text { hcp } \\
-1.49 \\
-0.49 \\
-0.97\end{array}$ & $\begin{array}{c}\mathbf{Z r}_{\text {hcp }} \mathbf{s v}^{\#} \\
3.28 \\
0.36 \\
0.65\end{array}$ & $\begin{array}{c}\text { Nb_pv }{ }^{* \#} \\
\text { bcc } \\
2.94 \\
2.77 \\
2.94 \\
(3.07)\end{array}$ & $\begin{array}{c}\text { Mo_pv }{ }^{* \#} \\
\text { bcc } \\
2.90 \\
2.79 \\
2.95 \\
(3.1)\end{array}$ & $\begin{array}{c}\text { Tc_pv } \\
\text { hcp } \\
-3.46 \\
-3.15 \\
-3.04\end{array}$ & $\begin{array}{c}\text { Ru } \\
\text { hcp } \\
-13.18 \\
-8.29 \\
-12.96\end{array}$ & $\begin{array}{c}\mathbf{R h} \\
\text { fcc } \\
-2.73 \\
-2.34 \\
-2.51\end{array}$ & $\begin{array}{c}\mathbf{P d}^{\#} \\
\text { fcc } \\
1.32 \\
1.07 \\
1.27\end{array}$ & $\begin{array}{c}\mathbf{A g}^{\#} \\
\text { fcc } \\
0.90 \\
0.64 \\
0.84\end{array}$ & $\begin{array}{c}\text { Cd } \\
\text { hcp } \\
-0.18 \\
-0.04 \\
-0.10\end{array}$ & $\begin{array}{c}\text { In_d }^{\#} \\
\text { tetr } \\
0.40 \\
0.33 \\
0.39\end{array}$ & $\begin{array}{c}\text { Sn_d }{ }^{\#} \\
\text { diamond } \\
0.28 \\
0.16 \\
0.34\end{array}$ & $\begin{array}{c}\mathbf{S b}^{* \#} \\
\text { rhomb } \\
0.42 \\
0.17 \\
0.43\end{array}$ & $\begin{array}{c}\text { Te } \\
\text { hex } \\
-0.26 \\
-1.35 \\
-0.32\end{array}$ & $\begin{array}{c}\text { I } \\
\text { complex } \\
-0.20 \\
-0.27 \\
-0.22\end{array}$ \\
\hline $\begin{array}{c}\text { Cs_sv }^{* \# \#} \\
\text { bcc } \\
0.34 \\
0.29 \\
0.29\end{array}$ & $\begin{array}{c}\text { Ba_sv } \\
\text { bcc } \\
1.00 \\
1.02 \\
1.09\end{array}$ & & $\begin{array}{c}\text { Hf_pv } \\
\text { hcp } \\
-0.25 \\
-0.71 \\
-0.51\end{array}$ & $\begin{array}{c}\text { Ta_pv }{ }^{* \#} \\
\text { bcc } \\
3.12 \\
2.93 \\
3.10 \\
(3.0)\end{array}$ & $\begin{array}{c}\text { W_pv } \mathbf{v}^{* \#} \\
\text { bcc } \\
3.27 \\
3.24 \\
3.39 \\
(3.5)\end{array}$ & $\begin{array}{c}\mathbf{R e} \\
\mathrm{hcp} \\
-3.61 \\
-3.43 \\
-3.36\end{array}$ & $\begin{array}{c}\text { Os_pv } \\
\text { hcp } \\
-18.20 \\
-18.11 \\
-18.10\end{array}$ & $\begin{array}{c}\mathbf{I r} \\
\text { fcc } \\
-8.92 \\
-8.85 \\
-8.95\end{array}$ & $\begin{array}{c}\mathbf{P t}^{\#} \\
\text { fcc } \\
0.98 \\
0.77 \\
0.95\end{array}$ & $\begin{array}{c}\mathbf{A u}^{\#} \\
\text { fcc } \\
0.72 \\
0.46 \\
0.68\end{array}$ & $\begin{array}{c}\mathbf{H g}^{* \#} \\
- \\
0.31 \\
0.14 \\
0.27\end{array}$ & $\begin{array}{c}\text { Tl_d }{ }^{* \#} \\
\text { hcp } \\
0.52 \\
0.40 \\
0.49\end{array}$ & $\begin{array}{c}\text { Pb_d }{ }^{\#} \\
\text { fcc } \\
0.51 \\
0.38 \\
0.52\end{array}$ & $\begin{array}{c}\mathbf{B i}_{\mathbf{B} \mathbf{d}^{* \#}} \\
\text { rhomb } \\
0.38 \\
0.20 \\
0.39\end{array}$ & $\begin{array}{c}\mathbf{P o}_{\text {Pubic }} \mathbf{d}^{\S} \\
0.50 \\
-0.21 \\
0.49\end{array}$ & $\begin{array}{c}\text { At_d } \\
- \\
-0.29 \\
-0.66 \\
0.70\end{array}$ \\
\hline $\begin{array}{c}\text { Fr_sv }{ }^{*} \\
\text { bcc } \\
-0.01 \\
-9.82 \\
-\end{array}$ & $\begin{array}{c}\mathbf{R a}_{\text {bcc }} \mathbf{s v}^{* \text { *H }} \\
1.11 \\
1.86 \\
0.45\end{array}$ & $\begin{array}{l}\mathbf{L a}^{\S} \\
\text { hex } \\
1.42 \\
1.50 \\
1.53\end{array}$ & $\begin{array}{c}\text { Ce_3 } \\
\text { fcc } \\
- \\
-1.31 \\
-1.13\end{array}$ & $\begin{array}{c}\text { Pr_3 } \\
\text { hex } \\
- \\
-1.48 \\
-1.58\end{array}$ & $\begin{array}{c}\begin{array}{c}\text { Nd_3 } \\
\text { hex }\end{array} \\
- \\
-1.64 \\
-1.69\end{array}$ & $\begin{array}{c}\text { Pm_3 } \\
\text { hex } \\
- \\
-1.77 \\
-1.94\end{array}$ & $\begin{array}{c}\text { Sm_3 } \\
\text { rhomb } \\
- \\
-1.79 \\
1.80\end{array}$ & $\begin{array}{c}\mathbf{E u}_{\mathbf{b} c \mathrm{3}} \mathbf{3}^{*} \\
- \\
-1.78 \\
1.92\end{array}$ & $\begin{array}{c}\text { Gd_3 } \\
\text { hcp } \\
- \\
1.58 \\
-2.12\end{array}$ & $\begin{array}{c}\text { Tb_3 } \\
\text { hcp } \\
- \\
-1.69 \\
1.77\end{array}$ & $\begin{array}{c}\text { Dy_3 } 3^{\otimes} \\
\text { hcp } \\
- \\
-1.49 \\
1.88\end{array}$ & $\begin{array}{c}\text { Ho_3 } \\
\text { hcp } \\
- \\
-1.22 \\
-1.76\end{array}$ & $\begin{array}{c}\mathbf{E r} \_3 \\
\text { hcp } \\
- \\
-0.91 \\
-1.52\end{array}$ & $\begin{array}{c}\text { Tm_3 } \\
\text { hcp } \\
- \\
-0.58 \\
-1.23\end{array}$ & $\begin{array}{c}\text { Yb_2 } 2^{\#} \\
\text { fcc } \\
- \\
0.95 \\
0.95\end{array}$ & $\begin{array}{c}\text { Lu_3 } \\
\text { hcp } \\
- \\
0.07 \\
-1.24\end{array}$ \\
\hline & & $\begin{array}{c}\text { Ac } \\
\text { fcc } \\
1.69 \\
-1.25 \\
1.81\end{array}$ & $\begin{array}{c}\mathbf{T h}^{\#} \\
\text { fcc } \\
0.98 \\
0.92 \\
1.10\end{array}$ & $\begin{array}{c}\mathbf{P a}^{\#} \\
\text { tetr } \\
0.15 \\
0.38 \\
0.53\end{array}$ & $\begin{array}{c}\mathbf{U} \\
\text { complex } \\
1.41 \\
-2.24 \\
1.48\end{array}$ & $\begin{array}{c}\mathbf{N p}^{*} \\
\text { complex } \\
-0.11 \\
-1.46 \\
0.03\end{array}$ & $\mathbf{P u}$ & Am & $\mathbf{C m}$ & Bk & Cf & Es & Fm & Md & No & $\mathbf{L r}$ \\
\hline
\end{tabular}


Table 2. Calculated vacancy formation energies/enthalpies at $0 \mathrm{~K}\left(H_{\mathrm{Va}}^{\mathrm{F}}\right.$, eV) of fcc structure together with the presently suggested experimental data in parentheses, see Supplemental Materials for details. Note that (i) the superscript * indicates the stable or metastable structure by elastic constants [36]; (ii) \# indicates the structure with a positive $H_{\mathrm{Va}}^{\mathrm{F}}$ and a smaller energy difference between two different vacancy structures $\left(\Delta E_{\mathrm{Va} 1-\mathrm{V} a 2}<1\right.$ meV); (iii) $\S$ indicates $\Delta E_{\mathrm{Va} 1-}$ $\mathrm{Va} 2>4 \mathrm{meV}$; and (iv) $\otimes$ indicates that only vibrational contribution by Debye model is used to calculate thermodynamic properties.

\begin{tabular}{|c|c|c|c|c|c|c|c|c|c|c|c|c|c|c|c|c|}
\hline $\begin{array}{l}\mathbf{L i}^{* \#} \\
0.65 \\
0.61 \\
0.62\end{array}$ & $\begin{array}{l}\mathbf{B e} \mathbf{*}^{* \#} \\
0.14 \\
0.02 \\
0.10\end{array}$ & \multirow{2}{*}{\multicolumn{3}{|c|}{4}} & \multirow{2}{*}{\multicolumn{4}{|c|}{$\begin{array}{l}\text { Calc. } H_{\mathrm{Va}}^{\mathrm{F}} \text { of fcc structure by LDA } \\
\text { Calc. } H_{\mathrm{Va}}^{\mathrm{F}} \text { of fcc structure by PBE } \\
\text { Calc. } H_{\mathrm{Va}}^{\mathrm{F}} \text { of fcc structure by PBEsol } \\
\text { Expt. } H_{\mathrm{Va}}^{\mathrm{F}} \text { of fcc structure if available }\end{array}$}} & & & & $\begin{array}{c}\text { B } \\
-3.41 \\
-3.20 \\
-2.72\end{array}$ & $\begin{array}{c}\mathbf{C}^{\S} \\
-1.01 \\
-0.99 \\
-0.95\end{array}$ & $\mathbf{N}$ & $\mathbf{O}$ & $\mathbf{F}$ \\
\hline $\begin{array}{l}\mathbf{N a * \#} \\
0.42 \\
0.40 \\
0.43\end{array}$ & $\begin{array}{c}\text { Mg*\# } \\
0.89 \\
0.83 \\
0.89\end{array}$ & & & & & & & & & & & $\begin{array}{c}\mathbf{A l}^{* \#} \\
0.68 \\
0.63 \\
0.74 \\
(0.7)\end{array}$ & $\begin{array}{c}\mathbf{S i} \\
-0.06 \\
-0.11 \\
0.02\end{array}$ & $\begin{array}{c}\mathbf{P}^{\S} \\
-0.56 \\
-0.91 \\
-0.76\end{array}$ & $\begin{array}{c}\mathbf{S}^{\S} \\
-3.13 \\
-0.27 \\
-0.07\end{array}$ & Cl \\
\hline $\begin{array}{l}\mathbf{K}^{* \#} \\
0.38 \\
0.35 \\
0.38\end{array}$ & $\begin{array}{l}\mathbf{C a}^{* \#} \\
1.18 \\
1.16 \\
1.21\end{array}$ & $\begin{array}{l}\mathbf{S c}^{* \#} \\
1.82 \\
1.76 \\
1.84\end{array}$ & $\begin{array}{l}\mathbf{T i}^{* \#} \\
2.06 \\
1.95 \\
2.07\end{array}$ & $\begin{array}{l}\mathbf{V}^{\#} \\
1.47 \\
1.69 \\
1.69\end{array}$ & $\begin{array}{l}\mathbf{C r}^{\#} \\
1.57 \\
1.58 \\
1.67\end{array}$ & $\begin{array}{l}\mathbf{M n}^{* * \#} \\
2.63 \\
2.44 \\
2.64\end{array}$ & $\begin{array}{l}\mathbf{F e}^{* \#} \\
2.62 \\
1.86 \\
2.36\end{array}$ & $\begin{array}{c}\mathbf{C o}^{* * \# \otimes} \\
2.11 \\
1.83 \\
2.05\end{array}$ & $\begin{array}{c}\mathbf{N i}^{* \#} \\
1.68 \\
1.46 \\
1.65 \\
(1.79)\end{array}$ & $\begin{array}{c}\mathbf{C u}^{* \#} \\
1.25 \\
1.06 \\
1.24 \\
(1.28)\end{array}$ & $\begin{array}{c}\mathbf{Z n}^{\#} \\
0.39 \\
0.34 \\
0.43\end{array}$ & $\begin{array}{c}\mathbf{G a}^{\#} \\
0.19 \\
0.20 \\
0.24\end{array}$ & $\begin{array}{c}\mathbf{G e}^{\#} \\
0.19 \\
0.12 \\
0.21\end{array}$ & $\begin{array}{c}\text { As } \\
-0.52 \\
-0.45 \\
-0.43\end{array}$ & $\begin{array}{c}\text { Se } \\
0.12 \\
-0.10 \\
0.05\end{array}$ & $\begin{array}{c}\mathbf{B r} \\
-0.21 \\
-0.85 \\
-0.39\end{array}$ \\
\hline $\begin{array}{c}\mathbf{R b}^{\text {*\# }} \\
0.35 \\
0.32 \\
0.25\end{array}$ & $\begin{array}{l}\mathbf{S r}^{* \#} \\
1.09 \\
0.97 \\
1.05\end{array}$ & $\begin{array}{c}\mathbf{Y}^{\text {*\# }} \\
1.87 \\
1.74 \\
1.84\end{array}$ & $\begin{array}{l}\mathbf{Z r}^{* \#} \\
2.07 \\
2.08 \\
2.15\end{array}$ & $\begin{array}{l}\mathbf{N b}^{\#} \\
1.40 \\
1.49 \\
1.53\end{array}$ & $\begin{array}{l}\mathbf{M o}^{\#} \\
1.89 \\
1.74 \\
1.91\end{array}$ & $\begin{array}{l}\mathbf{T c}^{* \#} \\
2.96 \\
2.72 \\
2.92\end{array}$ & $\begin{array}{l}\mathbf{R u}^{* \#} \\
2.97 \\
2.63 \\
2.95\end{array}$ & $\begin{array}{c}\mathbf{R h}^{* \# \otimes} \\
2.06 \\
1.76 \\
2.01 \\
(2.5)\end{array}$ & $\begin{array}{l}\mathbf{P d}^{* \#} \\
1.44 \\
1.17 \\
1.40 \\
(1.7)\end{array}$ & $\begin{array}{c}\mathbf{A g}^{* \#} \\
1.05 \\
0.79 \\
1.01 \\
(1.11)\end{array}$ & $\begin{array}{c}\mathbf{C d}^{\#} \\
0.36 \\
0.30 \\
0.40\end{array}$ & $\begin{array}{c}\mathbf{I n}^{\#} \\
0.33 \\
0.31 \\
0.39\end{array}$ & $\begin{array}{l}\mathbf{S n}^{* \#} \\
0.36 \\
0.26 \\
0.38\end{array}$ & $\begin{array}{c}\text { Sb } \\
-0.29 \\
-0.39 \\
-0.20\end{array}$ & $\begin{array}{c}\mathbf{T e}^{\#} \\
0.37 \\
0.12 \\
0.36\end{array}$ & $\begin{array}{c}\text { I } \\
0.10 \\
-0.44 \\
-\end{array}$ \\
\hline $\begin{array}{c}\mathbf{C s}^{* \#} \\
0.37 \\
0.31 \\
0.34\end{array}$ & $\begin{array}{l}\mathbf{B a}^{* \#} \\
1.20 \\
1.09 \\
1.14\end{array}$ & & $\begin{array}{l}\mathbf{H f}^{* \#} \\
2.19 \\
2.14 \\
2.29\end{array}$ & $\begin{array}{l}\mathbf{T a}^{\mathbf{\#}} \\
2.26 \\
2.46 \\
2.48\end{array}$ & $\begin{array}{c}\mathbf{W}^{\#} \\
2.26 \\
2.15 \\
2.32\end{array}$ & $\begin{array}{c}\mathbf{R e}^{* \# \otimes} \\
3.32 \\
3.08 \\
3.35\end{array}$ & $\begin{array}{c}\mathbf{O s}^{* \# \otimes} \\
3.40 \\
3.08 \\
3.39\end{array}$ & $\begin{array}{c}\mathbf{I r}^{* \# \otimes} \\
1.91 \\
1.63 \\
1.89\end{array}$ & $\begin{array}{c}\mathbf{P t}^{* \#} \\
0.86 \\
0.63 \\
0.84 \\
(1.35)\end{array}$ & $\begin{array}{c}\mathbf{A u}^{* \#} \\
0.60 \\
0.39 \\
0.57 \\
(0.93)\end{array}$ & $\begin{array}{c}\mathbf{H g}^{\#} \\
0.14 \\
- \\
0.12\end{array}$ & $\begin{array}{c}\mathbf{T l}^{\#} \\
0.56 \\
0.41 \\
0.54\end{array}$ & $\begin{array}{c}\mathbf{P b}^{* \#} \\
0.52 \\
0.45 \\
0.53 \\
(0.58)\end{array}$ & $\begin{array}{c}\mathbf{B i} \\
-0.01 \\
-0.14 \\
0.02\end{array}$ & $\begin{array}{c}\text { Po } \\
0.75 \\
-3.89 \\
-1.19\end{array}$ & $\begin{array}{c}\text { At } \\
0.07 \\
-0.47 \\
0.40\end{array}$ \\
\hline $\begin{array}{c}\mathbf{F r} \\
7.84 \\
-1.92 \\
2.19\end{array}$ & $\begin{array}{c}\mathbf{R a} \\
-2.22 \\
1.06 \\
10.79\end{array}$ & $\begin{array}{c}\mathbf{L a}^{* \#} \\
1.47 \\
1.46 \\
1.52\end{array}$ & $\begin{array}{c}\mathbf{C e}^{* \#} \\
- \\
1.60 \\
1.63 \\
(0.72)\end{array}$ & $\begin{array}{c}\mathbf{P r}^{* \#} \\
- \\
1.65 \\
1.69\end{array}$ & $\begin{array}{c}\mathbf{N d}^{* \#} \\
- \\
1.68 \\
1.74\end{array}$ & $\begin{array}{c}\mathbf{P m}^{* \#} \\
- \\
1.70 \\
1.80\end{array}$ & $\begin{array}{c}\mathbf{S m}^{* \#} \\
- \\
1.70 \\
1.81\end{array}$ & $\begin{array}{c}\mathbf{E u}^{* \#} \\
- \\
1.73 \\
1.83\end{array}$ & $\begin{array}{c}\mathbf{G d}^{* \#} \\
- \\
1.72 \\
1.84\end{array}$ & $\begin{array}{c}\mathbf{T b}^{* \#} \\
- \\
1.72 \\
1.84\end{array}$ & $\begin{array}{c}\mathbf{D y}^{*} \# \otimes \\
- \\
1.71 \\
1.84\end{array}$ & $\begin{array}{c}\mathbf{H o}^{* \#} \\
- \\
1.70 \\
1.83\end{array}$ & $\begin{array}{c}\mathbf{E r}^{* \#} \\
- \\
1.70 \\
1.82\end{array}$ & $\begin{array}{c}\mathbf{T m}^{* \# \#} \\
- \\
1.69 \\
1.80\end{array}$ & $\begin{array}{c}\mathbf{Y b}^{*} \\
- \\
-1.41 \\
1.27\end{array}$ & $\begin{array}{c}\mathbf{L u}^{* \#} \\
- \\
1.75 \\
1.81\end{array}$ \\
\hline & & $\begin{array}{l}\mathbf{A c}^{* \# \#} \\
1.48 \\
1.45 \\
1.50\end{array}$ & $\begin{array}{c}\mathbf{T h}^{*}{ }^{*} \\
2.33 \\
2.19 \\
2.34 \\
(1.28)\end{array}$ & $\begin{array}{l}\mathbf{P a}^{* \#} \\
1.44 \\
1.62 \\
1.57\end{array}$ & $\begin{array}{c}\mathbf{U} \\
-1.58 \\
-0.06 \\
-0.97\end{array}$ & $\begin{array}{c}\text { Np } \\
-7.99 \\
0.16 \\
-5.14\end{array}$ & $\mathbf{P u}$ & Am & $\mathbf{C m}$ & Bk & Cf & Es & Fm & Md & No & $\mathbf{L r}$ \\
\hline
\end{tabular}


Table 3. Calculated vacancy formation energies/enthalpies at $0 \mathrm{~K}\left(H_{\mathrm{Va}}^{\mathrm{F}}\right.$, eV) of hcp structure together with the presently suggested experimental data in parentheses see Supplemental Materials for details. Note that (i) the superscript * indicates the stable or metastable structure by elastic constants [36]; (ii) \# indicates the structure with a positive $H_{\mathrm{Va}}^{\mathrm{F}}$ and a smaller energy difference between two different vacancy structures $\left(\Delta E_{\mathrm{Va}}\right.$-Va2 $<1$ meV); (iii) $\S$ indicates $\Delta E_{\mathrm{Va} 1-}$ $\mathrm{Va2}>4 \mathrm{meV}$; and (iv) $\otimes$ indicates that only vibrational contribution by Debye model is used to calculate thermodynamic properties.

\begin{tabular}{|c|c|c|c|c|c|c|c|c|c|c|c|c|c|c|c|c|}
\hline $\begin{array}{l}\mathbf{L i}^{* \#} \\
0.62 \\
0.60 \\
0.61\end{array}$ & $\begin{array}{c}\mathbf{B e}^{* *} \\
1.02 \\
0.92 \\
0.99 \\
(1.11)\end{array}$ & \multirow{2}{*}{\multicolumn{3}{|c|}{$\leftarrow$}} & \multirow{2}{*}{\multicolumn{4}{|c|}{$\begin{array}{l}\text { Calc. } H_{\mathrm{Va}}^{\mathrm{F}} \text { of hcp structure by LDA } \\
\text { Calc. } H_{\mathrm{Va}}^{\mathrm{F}} \text { of hcp structure by PBE } \\
\text { Calc. } H_{\mathrm{Va}}^{\mathrm{F}} \text { of hcp structure by PBEsol } \\
\text { Expt. } H_{\mathrm{Va}}^{\mathrm{F}} \text { of hep structure if available }\end{array}$}} & & & & $\begin{array}{c}\mathbf{B}^{\S} \\
-2.26 \\
-2.55 \\
-2.36\end{array}$ & $\begin{array}{c}\mathbf{C}^{\S} \\
-186.72 \\
-107.24 \\
-149.28\end{array}$ & $\mathbf{N}$ & $\mathbf{O}$ & \multirow[b]{2}{*}{ Cl } \\
\hline $\begin{array}{c}\mathbf{N a}^{* \#} \\
0.42 \\
0.40 \\
0.43\end{array}$ & $\begin{array}{c}\mathbf{M g}^{* \#} \\
0.83 \\
0.73 \\
0.80 \\
(0.8)\end{array}$ & & & & & & & & & & & $\begin{array}{l}\mathbf{A l}^{\S} \\
0.63 \\
0.57 \\
0.69\end{array}$ & $\begin{array}{c}\mathbf{S i}^{*} \\
0.03 \\
-0.01 \\
0.11\end{array}$ & $\begin{array}{c}\mathbf{P}^{\S} \\
-0.05 \\
-1.12 \\
-0.05\end{array}$ & $\begin{array}{c}\mathbf{S}^{* 8} \\
0.38 \\
0.14 \\
0.36\end{array}$ & \\
\hline $\begin{array}{l}\mathbf{K}^{* \#} \\
0.42 \\
0.38 \\
0.40\end{array}$ & $\begin{array}{l}\mathbf{C a}^{* *} \\
1.14 \\
1.05 \\
1.11\end{array}$ & $\begin{array}{l}\text { Sc*\# } \\
1.97 \\
1.90 \\
1.98\end{array}$ & $\begin{array}{l}\mathbf{T i}^{* \#} \\
2.07 \\
2.09 \\
2.16 \\
(1.5)\end{array}$ & $\begin{array}{l}\mathbf{V}^{\#} \\
1.67 \\
1.67 \\
1.77\end{array}$ & $\begin{array}{l}\mathbf{C r}^{\#} \\
1.63 \\
1.61 \\
1.72\end{array}$ & $\begin{array}{c}\text { Mn*\# } \\
2.64 \\
2.34 \\
2.66\end{array}$ & $\begin{array}{l}\mathbf{F e}^{* \#} \\
2.73 \\
2.53 \\
2.73\end{array}$ & $\begin{array}{c}\text { Co** } \\
2.15 \\
1.91 \\
2.13 \\
(1.35)\end{array}$ & $\begin{array}{l}\mathbf{N i}^{* \#} \\
1.58 \\
1.35 \\
1.54\end{array}$ & $\begin{array}{l}\mathbf{C u}^{* *} \\
1.29 \\
1.07 \\
1.27\end{array}$ & $\begin{array}{c}\mathbf{Z n}{ }^{* \#} \\
0.53 \\
0.48 \\
0.52 \\
(0.54)\end{array}$ & $\begin{array}{l}\mathbf{G a}^{\#} \\
0.23 \\
0.27 \\
0.35\end{array}$ & $\begin{array}{c}\mathbf{G e}^{* \#} \\
0.26 \\
0.19 \\
0.29\end{array}$ & $\begin{array}{c}\text { As } \\
-0.79 \\
-1.07 \\
-0.65\end{array}$ & $\begin{array}{c}\mathbf{S e}^{* \S} \\
0.01 \\
-0.02 \\
0.17\end{array}$ & $\begin{array}{c}\mathbf{B r}^{\S} \\
-0.44 \\
-0.63 \\
-0.63\end{array}$ \\
\hline $\begin{array}{c}\mathbf{R b}^{\text {*\# }} \\
0.38 \\
0.35 \\
0.38\end{array}$ & $\begin{array}{l}\mathbf{S r}^{* \#} \\
1.06 \\
0.99 \\
1.02\end{array}$ & $\begin{array}{c}\mathbf{Y}^{* \#} \\
1.88 \\
1.87 \\
1.93\end{array}$ & $\begin{array}{l}\mathbf{Z r}^{* \#} \\
2.06 \\
2.01 \\
2.11 \\
(1.7)\end{array}$ & $\begin{array}{l}\mathbf{N b}^{\#} \\
1.90 \\
1.89 \\
1.98\end{array}$ & $\begin{array}{l}\mathbf{M o}^{\#} \\
1.83 \\
1.80 \\
1.95\end{array}$ & $\begin{array}{l}\text { Te*\# } \\
3.09 \\
2.85 \\
3.09\end{array}$ & $\begin{array}{l}\mathbf{R u}^{* \#} \\
3.10 \\
2.78 \\
3.09\end{array}$ & $\begin{array}{c}\mathbf{R h}^{* \# \otimes} \\
1.66 \\
1.40 \\
1.63\end{array}$ & $\begin{array}{c}\mathbf{P d}^{* \$} \\
1.37 \\
1.17 \\
1.39\end{array}$ & $\begin{array}{c}\mathbf{A g}^{* *} \\
1.06 \\
0.79 \\
1.01\end{array}$ & $\begin{array}{c}\mathbf{C d}^{* *} \\
0.29 \\
0.15 \\
0.25 \\
(0.46)\end{array}$ & $\begin{array}{c}\mathbf{I n}^{\#} \\
0.38 \\
0.35 \\
0.40\end{array}$ & $\begin{array}{c}\text { Sn*\$ } \\
0.44 \\
0.34 \\
0.47\end{array}$ & $\begin{array}{c}\mathbf{S b} \\
-0.14 \\
-2.50 \\
-1.15\end{array}$ & $\begin{array}{l}\mathbf{T e}^{* \S} \\
0.48 \\
0.23 \\
0.45\end{array}$ & $\begin{array}{c}\text { I } \\
-0.31 \\
-0.73 \\
-0.33\end{array}$ \\
\hline $\begin{array}{l}\text { Cs*\# }^{* \#} \\
0.38 \\
0.31 \\
0.35\end{array}$ & $\begin{array}{c}\text { Ba** }^{* *} \\
1.06 \\
1.11 \\
1.15\end{array}$ & & $\begin{array}{c}\text { Hf }^{* \# \otimes} \\
2.19 \\
2.24 \\
2.31 \\
(1.8)\end{array}$ & $\begin{array}{c}\mathbf{T a}^{\#} \\
2.40 \\
2.32 \\
2.47\end{array}$ & $\begin{array}{c}\mathbf{W}^{\#} \\
2.35 \\
2.28 \\
2.46\end{array}$ & $\begin{array}{c}\mathbf{R e}^{* \# \otimes} \\
3.64 \\
3.39 \\
3.66 \\
(2.3)\end{array}$ & $\begin{array}{c}\text { Os }^{* \# \otimes} \\
3.56 \\
3.24 \\
3.55\end{array}$ & $\begin{array}{c}\mathbf{I r}^{* \# \otimes} \\
1.33 \\
1.08 \\
1.32\end{array}$ & $\begin{array}{c}\mathbf{P t}^{\#} \\
0.96 \\
0.75 \\
0.93\end{array}$ & $\begin{array}{c}\mathbf{A u}^{* \#} \\
0.67 \\
0.42 \\
0.63\end{array}$ & $\begin{array}{c}\mathbf{H g} \text { ** } \\
0.06 \\
0.06 \\
0.13\end{array}$ & $\begin{array}{c}\text { Tl*\# } \\
0.54 \\
0.44 \\
0.53 \\
(0.46)\end{array}$ & $\begin{array}{c}\mathbf{P b}^{* 8} \\
0.64 \\
0.48 \\
0.63\end{array}$ & $\begin{array}{c}\mathbf{B i} * 8 \\
0.21 \\
0.08 \\
0.26\end{array}$ & $\begin{array}{c}\mathbf{P o}^{\S} \\
0.28 \\
2.84 \\
0.42\end{array}$ & $\begin{array}{c}\text { At } \\
-0.47 \\
-1.93 \\
-0.78\end{array}$ \\
\hline $\begin{array}{c}\mathbf{F r} \\
3.48 \\
-0.12 \\
3.73\end{array}$ & $\begin{array}{c}\mathbf{R a} \\
-2.68 \\
0.87 \\
0.77\end{array}$ & $\begin{array}{c}\mathbf{L a}^{* \#} \\
0.73 \\
1.41 \\
1.09\end{array}$ & $\begin{array}{c}\mathrm{Ce}^{* \#} \\
- \\
1.50 \\
1.58\end{array}$ & $\begin{array}{c}\text { Pr*\# }^{* \#} \\
- \\
1.53 \\
1.60\end{array}$ & $\begin{array}{c}\mathbf{N d}^{* \#} \\
- \\
1.57 \\
1.64\end{array}$ & $\begin{array}{c}\mathbf{P m}^{* \#} \\
- \\
1.56 \\
1.68\end{array}$ & $\begin{array}{c}\mathbf{S m}^{* \#} \\
- \\
1.61 \\
1.69\end{array}$ & $\begin{array}{c}\mathbf{E} \mathbf{u}^{* \#} \\
- \\
1.65 \\
1.72\end{array}$ & $\begin{array}{c}\mathbf{G d}^{* \# \otimes} \\
- \\
1.70 \\
1.77\end{array}$ & $\begin{array}{c}\mathbf{T b}^{* \#} \\
- \\
1.73 \\
1.80\end{array}$ & $\begin{array}{c}\text { Dy*\# } \\
- \\
1.78 \\
1.85\end{array}$ & $\begin{array}{c}\mathbf{H o}^{* \#} \\
- \\
1.80 \\
1.86\end{array}$ & $\begin{array}{c}\mathbf{E r}^{* \# \otimes} \\
- \\
1.83 \\
1.91\end{array}$ & $\begin{array}{c}\mathbf{T m}^{* *} \\
- \\
1.82 \\
1.92\end{array}$ & $\begin{array}{c}\mathbf{Y b}^{* \#} \\
- \\
1.03 \\
1.19\end{array}$ & $\begin{array}{c}\mathbf{L u}^{* \#} \\
- \\
1.85 \\
1.93\end{array}$ \\
\hline & & $\begin{array}{c}\text { Ac*\# }^{* *} \\
1.56 \\
1.45 \\
1.57\end{array}$ & $\begin{array}{l}\text { Th}^{* \#} \\
2.25 \\
2.05 \\
2.23\end{array}$ & $\begin{array}{l}\mathbf{P a}^{* \#} \\
2.29 \\
2.24 \\
2.36\end{array}$ & $\begin{array}{c}\mathbf{U}^{* \#} \\
0.83 \\
1.10 \\
1.01\end{array}$ & $\begin{array}{c}\mathbf{N p}^{*} \\
-22.34 \\
1.69 \\
-18.66\end{array}$ & $\mathbf{P u}$ & Am & $\mathrm{Cm}$ & Bk & Cf & Es & $\mathbf{F m}$ & Md & No & $\mathbf{L r}$ \\
\hline
\end{tabular}


Table 4. Calculated vacancy migration energies/enthalpies at $0 \mathrm{~K}\left(H_{\mathrm{Va}}^{\mathrm{M}}\right.$, eV) by PBEsol and CINEB together with the presently suggested experimental data in parentheses, see Supplemental Materials for details. Note that calculated $H_{\mathrm{Va}}^{\mathrm{M}}$ results are only for stable and metastable structures, and $\oplus$ indicates a relaxed result from CINEB directly.

\begin{tabular}{|c|c|c|c|c|c|c|c|c|c|c|c|c|c|c|c|c|}
\hline $\begin{array}{c}\mathbf{L i} \\
0.05 \\
0.07 \\
0.11 \\
0.13 \\
(0.038)^{\mathrm{B}}\end{array}$ & $\begin{array}{c}\mathbf{B e} \\
- \\
0.96 \\
0.73 \\
0.92 \\
(0.8)^{\mathrm{H}}\end{array}$ & \multirow{2}{*}{\multicolumn{7}{|c|}{$\begin{array}{c}H_{\mathrm{Va}}^{\mathrm{M}} \text { of bcc structure by PBEsol } \\
H_{\mathrm{Va}}^{\mathrm{M}} \text { of fcc structure by PBEsol } \\
H_{\mathrm{Va}}^{\mathrm{M}} \text { of hcp structure }(\perp c \text { axis) by PBEsol } \\
H_{\mathrm{Va}}^{\mathrm{M}} \text { of hcp structure }(/ / c \text { axis) by PBEsol } \\
\text { Expt. } H_{\mathrm{Va}}^{\mathrm{M}} \text { of }(\mathrm{bcc})^{\mathrm{B}},(\mathrm{fcc})^{\mathrm{F}} \text { or }(\mathrm{hcp})^{\mathrm{H}} \text { structure }\end{array}$}} & & & & B & $\mathbf{C}$ & $\mathbf{N}$ & O & $\mathbf{F}$ \\
\hline $\begin{array}{c}\mathbf{N a} \\
0.09 \\
0.06 \\
0.11 \\
0.13 \\
(0.03)^{\mathbf{B}}\end{array}$ & $\begin{array}{c}\text { Mg } \\
0.06 \\
0.36 \\
0.40 \\
0.42 \\
(0.5)^{\mathrm{H}}\end{array}$ & & & & & & & & & & & $\begin{array}{c}\text { Al } \\
- \\
0.57 \\
- \\
- \\
(0.61)^{\mathrm{F}}\end{array}$ & $\mathbf{S i}$ & $\mathbf{P}$ & $\mathbf{S}$ & Cl \\
\hline $\begin{array}{c}\mathbf{K} \\
0.05^{\oplus} \\
0.08 \\
0.17 \\
0.17 \\
(0.036)^{\mathrm{B}}\end{array}$ & $\begin{array}{c}\mathbf{C a} \\
0.22 \\
0.44 \\
0.41 \\
0.44\end{array}$ & $\begin{array}{c}\mathbf{S c} \\
- \\
0.56 \\
0.63 \\
0.64\end{array}$ & $\begin{array}{c}\mathbf{T i} \\
- \\
0.32 \\
0.47 \\
0.57\end{array}$ & $\begin{array}{c}\mathbf{V} \\
0.46 \\
- \\
- \\
- \\
(0.93)^{\mathrm{B}}\end{array}$ & $\begin{array}{c}\mathbf{C r} \\
0.90 \\
- \\
- \\
- \\
(0.95)^{\mathrm{B}}\end{array}$ & $\begin{array}{c}\text { Mn } \\
- \\
0.46 \\
0.58 \\
0.21\end{array}$ & $\begin{array}{c}\mathbf{F e} \\
0.73 \\
- \\
1.57 \\
0.88 \\
(0.8)^{\mathrm{B}}\end{array}$ & $\begin{array}{c}\text { Co } \\
- \\
1.05 \\
0.98 \\
0.97 \\
(0.72)^{\mathrm{H}}\end{array}$ & $\begin{array}{c}\mathbf{N i} \\
- \\
1.12 \\
0.92 \\
1.02 \\
(1.1)^{\mathrm{F}}\end{array}$ & $\begin{array}{c}\mathbf{C u} \\
0.36 \\
0.71 \\
0.70 \\
0.78 \\
(0.7)^{\mathrm{F}}\end{array}$ & $\begin{array}{c}\mathbf{Z n} \\
- \\
0.29 \\
0.26^{\oplus} \\
0.23^{\oplus} \\
(0.42)^{\mathrm{H}}\end{array}$ & $\begin{array}{c}\mathbf{G a} \\
0.06 \\
0.16 \\
0.17 \\
0.18\end{array}$ & $\mathbf{G e}$ & As & Se & $\mathbf{B r}$ \\
\hline $\begin{array}{c}\mathbf{R b} \\
0.01 \\
0.21 \\
0.11 \\
0.13\end{array}$ & $\begin{array}{c}\mathbf{S r} \\
0.23 \\
0.45 \\
0.38 \\
0.41\end{array}$ & $\begin{array}{c}\mathbf{Y} \\
- \\
0.64 \\
0.56 \\
0.59\end{array}$ & $\begin{array}{c}\mathbf{Z r} \\
- \\
0.32 \\
0.49 \\
0.67\end{array}$ & $\begin{array}{c}\mathbf{N b} \\
0.43 \\
- \\
- \\
- \\
(0.9)^{\mathrm{B}}\end{array}$ & $\begin{array}{c}\text { Mo } \\
1.23 \\
- \\
- \\
- \\
(1.5)^{\mathrm{B}}\end{array}$ & $\begin{array}{c}\mathbf{T c} \\
- \\
0.93 \\
1.30 \\
0.73\end{array}$ & $\begin{array}{c}\mathbf{R u} \\
- \\
2.08 \\
2.42 \\
2.46\end{array}$ & $\begin{array}{c}\text { Rh } \\
- \\
1.94 \\
1.56 \\
1.71 \\
(1.5)^{\mathrm{F}}\end{array}$ & $\begin{array}{c}\text { Pd } \\
0.38 \\
1.03 \\
0.87 \\
0.92 \\
(1.03)^{\mathrm{F}}\end{array}$ & $\begin{array}{c}\text { Ag } \\
0.43 \\
0.59 \\
0.62 \\
0.69 \\
(0.66)^{\mathrm{F}}\end{array}$ & $\begin{array}{c}\text { Cd } \\
- \\
0.08 \\
0.23 \\
0.16 \\
(0.4)^{\mathrm{H}}\end{array}$ & $\begin{array}{c}\text { In } \\
0.19 \\
0.25 \\
0.24 \\
0.27\end{array}$ & $\begin{array}{c}\text { Sn } \\
0.28 \\
0.44 \\
0.27 \\
0.32\end{array}$ & $\begin{array}{c}\text { Sb } \\
0.06 \\
- \\
- \\
-\end{array}$ & $\mathbf{T e}$ & I \\
\hline $\begin{array}{c}\text { Cs } \\
0.12 \\
0.12 \\
0.12 \\
0.11\end{array}$ & $\begin{array}{c}\mathbf{B a} \\
0.19 \\
0.31 \\
0.36 \\
0.40\end{array}$ & & $\begin{array}{c}\text { Hf } \\
- \\
0.68 \\
0.88 \\
1.05\end{array}$ & $\begin{array}{c}\text { Ta } \\
0.75 \\
- \\
- \\
- \\
(1.1)^{\mathrm{B}}\end{array}$ & $\begin{array}{c}\text { W } \\
1.82 \\
- \\
- \\
- \\
(1.81)^{\mathrm{B}}\end{array}$ & $\begin{array}{c}\mathbf{R e} \\
- \\
1.83 \\
2.00 \\
1.25 \\
(2.2)^{\mathrm{H}}\end{array}$ & $\begin{array}{c}\text { Os } \\
- \\
3.06 \\
3.35 \\
3.48\end{array}$ & $\begin{array}{c}\mathbf{I r} \\
- \\
2.75 \\
2.04 \\
2.40\end{array}$ & $\begin{array}{c}\mathbf{P t} \\
0.16 \\
1.37 \\
- \\
- \\
(1.43)^{\mathrm{F}}\end{array}$ & $\begin{array}{c}\text { Au } \\
0.38 \\
0.67 \\
0.58 \\
0.67 \\
(0.71)^{\mathrm{F}}\end{array}$ & $\begin{array}{c}\mathbf{H g} \\
0.11 \\
- \\
0.05 \\
0.02\end{array}$ & $\begin{array}{c}\text { Tl } \\
0.48 \\
0.07 \\
0.22 \\
0.22\end{array}$ & $\begin{array}{c}\mathbf{P b} \\
- \\
0.50 \\
- \\
- \\
(0.43)^{\mathrm{F}}\end{array}$ & $\begin{array}{c}\mathbf{B i} \\
0.06 \\
- \\
0.36 \\
0.41\end{array}$ & Po & At \\
\hline \multirow[t]{2}{*}{ Fr } & $\begin{array}{c}\mathbf{R a} \\
1.13 \\
- \\
1.53 \\
1.58\end{array}$ & $\begin{array}{c}\mathbf{L a} \\
- \\
- \\
0.01 \\
0.18\end{array}$ & $\begin{array}{c}\text { Ce } \\
- \\
0.17 \\
-0.02 \\
0.24 \\
(0.87)^{\mathrm{F}}\end{array}$ & $\begin{array}{c}\mathbf{P r} \\
- \\
0.21 \\
0.00 \\
0.25\end{array}$ & $\begin{array}{c}\mathbf{N d} \\
- \\
0.30 \\
0.11 \\
0.32\end{array}$ & $\begin{array}{c}\mathbf{P m} \\
- \\
0.40 \\
0.17 \\
0.34\end{array}$ & $\begin{array}{c}\text { Sm } \\
- \\
0.49 \\
0.23 \\
0.37\end{array}$ & $\begin{array}{c}\mathbf{E u} \\
- \\
0.57 \\
0.29 \\
0.42\end{array}$ & $\begin{array}{c}\text { Gd } \\
- \\
0.60 \\
0.39 \\
0.51\end{array}$ & $\begin{array}{c}\text { Tb } \\
- \\
0.63 \\
0.44 \\
0.53\end{array}$ & $\begin{array}{c}\text { Dy } \\
- \\
0.66 \\
0.50 \\
0.57\end{array}$ & $\begin{array}{c}\text { Ho } \\
- \\
0.68 \\
0.53 \\
0.59\end{array}$ & $\begin{array}{c}\mathbf{E r} \\
- \\
0.71 \\
0.59 \\
0.63\end{array}$ & $\begin{array}{c}\mathbf{T m} \\
- \\
0.73 \\
0.64 \\
0.68\end{array}$ & $\begin{array}{c}\mathbf{Y b} \\
0.47 \\
- \\
0.57 \\
0.61\end{array}$ & $\begin{array}{c}\text { Lu } \\
- \\
0.74 \\
0.70 \\
0.74\end{array}$ \\
\hline & & $\begin{array}{c}\text { Ac } \\
- \\
0.34 \\
0.26 \\
0.40\end{array}$ & $\begin{array}{c}\text { Th } \\
- \\
1.13 \\
0.64 \\
0.90 \\
(2.04)^{\mathrm{F}}\end{array}$ & $\begin{array}{c}\mathbf{P a} \\
- \\
0.54 \\
0.59 \\
0.98\end{array}$ & $\mathbf{U}$ & Np & $\mathbf{P u}$ & Am & $\mathrm{Cm}$ & Bk & Cf & Es & Fm & Md & No & $\mathbf{L r}$ \\
\hline
\end{tabular}


Table 5. Arrhenius fitting parameters, see Eq. (1), of pre-exponential factor $\left(A_{\mathrm{Va}}^{\mathrm{D}}, \mathrm{cm}^{2} \mathrm{~s}^{-1}\right)$ and vacancy activation energy $\left(H_{\mathrm{Va}}^{\mathrm{Q}}\right.$, eV) for self diffusion coefficients of pure elements in bcc, fcc, and hcp structures according to the X-C of PBEsol. The fittings were performed in the temperature range of $0.7 T_{\mathrm{m}}-T_{\mathrm{m}}\left(T_{\mathrm{m}}\right.$ the melting point).

\begin{tabular}{|c|c|c|c|c|c|c|c|c|c|c|c|c|c|c|c|}
\hline $\begin{array}{c}\mathbf{L i} \\
0.14,0.62 \\
0.36,0.72 \\
0.36,0.75 \\
0.37,0.76\end{array}$ & $\begin{array}{c}\mathbf{B e} \\
- \\
1.05,1.07 \\
3.39,1.85 \\
3.87,2.00\end{array}$ & \multirow{2}{*}{\multicolumn{10}{|c|}{$\begin{array}{l}\text { Fitted } A_{\mathrm{Va}}^{\mathrm{D}} \text { and } H_{\mathrm{Va}}^{\mathrm{Q}} \text { of bcc structure by PBEsol } \\
\text { Fitted } A_{\mathrm{Va}}^{\mathrm{D}} \text { and } H_{\mathrm{Va}}^{\mathrm{Q}} \text { of fcc structure by PBEsol }\end{array}$}} & B & $\mathbf{C}$ & $\mathbf{N}$ & $\mathbf{O}$ \\
\hline $\begin{array}{c}\mathbf{N a} \\
0.87,0.47 \\
2.04,0.51 \\
12.82,0.62 \\
12.68,0.62\end{array}$ & \begin{tabular}{|c|}
$\mathbf{M g}$ \\
$0.76,0.71$ \\
$6.05,1.33$ \\
$17.93,1.28$ \\
$17.45,1.30$
\end{tabular} & & & & & & & & & & & $\begin{array}{c}\text { Al } \\
- \\
8.51,1.36 \\
- \\
-\end{array}$ & $\mathbf{S i}$ & $\mathbf{P}$ & $\mathbf{S}$ \\
\hline $\begin{array}{c}\mathbf{K} \\
0.55,0.34 \\
1.55,0.49 \\
2.52,0.60 \\
2.38,0.60\end{array}$ & $\begin{array}{c}\mathbf{C a} \\
2.40,1.19 \\
4.66,1.75 \\
5.97,1.63 \\
6.65,1.65\end{array}$ & $\begin{array}{c}\text { Sc } \\
- \\
2.14,2.54 \\
3.99,2.79 \\
3.52,2.79\end{array}$ & $\begin{array}{c}\mathbf{T i} \\
- \\
0.46,2.48 \\
1.00,2.76 \\
1.02,2.83\end{array}$ & $\left|\begin{array}{c}\mathbf{V} \\
1.83,3.30 \\
- \\
- \\
-\end{array}\right|$ & \begin{tabular}{c|c}
$\mathbf{C r}$ \\
$5.38,4.08$ \\
- \\
- \\
-
\end{tabular} & $\begin{array}{c}\text { Mn } \\
- \\
15.82,3.24 \\
7.76,3.08 \\
16.12,3.03\end{array}$ & $\begin{array}{c}\mathbf{F e} \\
11.75,3.30 \\
- \\
7.6 \mathrm{e} 4,3.95 \\
2.9 \mathrm{e} 5,3.95\end{array}$ & \begin{tabular}{|c|} 
Co \\
- \\
$34.44,3.27$ \\
$35.39,3.26$ \\
$37.21,3.25$
\end{tabular} & \begin{tabular}{|c|}
$\mathbf{N i}$ \\
- \\
$12.11,2.92$ \\
$14.85,2.65$ \\
$16.60,2.72$
\end{tabular} & \begin{tabular}{|c|}
$\mathbf{C u}$ \\
$2.12,1.53$ \\
$20.04,2.05$ \\
$22.03,2.09$ \\
$24.16,2.15$
\end{tabular} & $\begin{array}{c}\mathbf{Z n} \\
- \\
14.34,0.79 \\
8.3 \mathrm{e}-6,0.68 \\
9.6 \mathrm{e}-6,0.66\end{array}$ & $\begin{array}{c}\mathbf{G a} \\
0.06,0.35 \\
0.19,0.42 \\
0.22,0.55 \\
0.21,0.56\end{array}$ & Ge & As & Se \\
\hline $\begin{array}{c}\mathbf{R b} \\
0.98,0.32 \\
7.01,0.48 \\
3.32,0.52 \\
3.51,0.53\end{array}$ & $\begin{array}{c}\mathbf{S r} \\
3.26,1.25 \\
4.63,1.57 \\
0.71,1.43 \\
0.79,1.46\end{array}$ & $\begin{array}{c}\mathbf{Y} \\
- \\
2.16,2.62 \\
2.27,2.69 \\
2.12,2.71\end{array}$ & $\begin{array}{c}\mathbf{Z r} \\
- \\
0.45,2.56 \\
0.60,2.73 \\
0.75,2.87\end{array}$ & $\left|\begin{array}{c}\mathbf{N b} \\
3.45,3.62 \\
- \\
- \\
-\end{array}\right|$ & $\begin{array}{c}\text { Mo } \\
4.66,4.45 \\
- \\
- \\
-\end{array}$ & $\begin{array}{c}\mathbf{T c} \\
- \\
13.63,4.07 \\
6.53,4.18 \\
12.76,4.09\end{array}$ & $\begin{array}{c}\mathbf{R u} \\
- \\
48.58,5.22 \\
2.7 \mathrm{e} 2,5.86 \\
2.4 \mathrm{e} 2,5.89\end{array}$ & \begin{tabular}{|c|}
$\mathbf{R h}$ \\
- \\
$1.2 \mathrm{e} 2,4.19$ \\
$34.73,3.39$ \\
$38.54,3.49$
\end{tabular} & \begin{tabular}{|c|} 
Pd \\
$6.35,1.82$ \\
$10.32,2.52$ \\
$74.59,2.51$ \\
$82.50,2.54$
\end{tabular} & \begin{tabular}{|c|}
$\mathbf{A g}$ \\
$9.12,1.37$ \\
$94.92,1.71$ \\
$99.47,1.77$ \\
$1.2 \mathrm{e} 2,1.82$ \\
\end{tabular} & $\begin{array}{c}\text { Cd } \\
- \\
5.41,0.52 \\
6.7 \mathrm{e}-3,0.44 \\
6.7 \mathrm{e}-3,0.41\end{array}$ & \begin{tabular}{|c|} 
In \\
$0.64,0.61$ \\
$1.94,0.67$ \\
$1.91,0.67$ \\
$2.34,0.70$
\end{tabular} & $\begin{array}{c}\text { Sn } \\
2.04,0.65 \\
2.79,0.86 \\
1.72,0.79 \\
1.99,0.82\end{array}$ & $\begin{array}{c}\mathbf{S b} \\
9.5 \mathrm{e} 2,0.58 \\
- \\
- \\
-\end{array}$ & $\mathbf{T e}$ \\
\hline $\begin{array}{c}\text { Cs } \\
0.95,0.43 \\
1.61,0.48 \\
1.81,0.49 \\
1.67,0.48\end{array}$ & $\begin{array}{c}\text { Ba } \\
0.21,1.34 \\
0.42,1.43 \\
0.43,1.51 \\
0.45,1.54\end{array}$ & & $\begin{array}{c}\text { Hf } \\
- \\
2.30,3.14 \\
2.49,3.44 \\
2.81,3.55\end{array}$ & $\mid \begin{array}{c}\text { Ta } \\
3.97,4.14 \\
- \\
- \\
-\end{array}$ & \begin{tabular}{|c|}
$\mathbf{W}$ \\
$9.26,5.54$ \\
- \\
- \\
-
\end{tabular} & $\begin{array}{c}\mathbf{R e} \\
- \\
96.47,5.59 \\
17.17,5.33 \\
31.33,5.20\end{array}$ & $\begin{array}{c}\text { Os } \\
- \\
7.8 \mathrm{e} 2,6.89 \\
1.2 \mathrm{e} 2,7.19 \\
1.1 \mathrm{e} 2,7.28\end{array}$ & \begin{tabular}{|c|}
$\mathbf{I r}$ \\
- \\
$93.97,4.74$ \\
$44.35,3.63$ \\
$56.92,3.91$
\end{tabular} & \begin{tabular}{|c|} 
Pt \\
$5.07,1.28$ \\
$45.19,2.37$ \\
- \\
-
\end{tabular} & \begin{tabular}{|c|}
$\mathbf{A u}$ \\
$12.19,1.19$ \\
$64.01,1.35$ \\
$48.42,1.32$ \\
$61.67,1.38$
\end{tabular} & $\begin{array}{c}\mathbf{H g} \\
4.3 \mathrm{e} 3,0.42 \\
- \\
6.11,0.19 \\
6.02,0.18\end{array}$ & \begin{tabular}{|c|}
$\mathbf{T l}$ \\
$4.59,1.03$ \\
$22.74,0.65$ \\
$71.20,0.80$ \\
$1.3 \mathrm{e} 2,0.80$
\end{tabular} & $\begin{array}{c}\mathbf{P b} \\
- \\
4.84,1.07 \\
- \\
-\end{array}$ & \begin{tabular}{|c|}
$\mathbf{B i}$ \\
$7.22,0.48$ \\
- \\
$8.96,0.67$ \\
$11.25,0.70$
\end{tabular} & Po \\
\hline & $\begin{array}{c}\mathbf{L a} \\
- \\
- \\
2.0 \mathrm{e}-2,1.17 \\
1.7 \mathrm{e}-2,1.33\end{array}$ & $\begin{array}{c}\text { Ce } \\
- \\
0.11,1.86 \\
0.27,1.68 \\
0.75,1.91\end{array}$ & $\begin{array}{c}\text { Pr } \\
- \\
0.16,1.98 \\
0.38,1.73 \\
0.80,1.94\end{array}$ & $\begin{array}{c}\mathbf{N d} \\
- \\
0.29,2.15 \\
0.46,1.89 \\
0.80,2.05\end{array}$ & \begin{tabular}{|c|} 
Pm \\
- \\
$0.46,2.31$ \\
$0.56,1.99$ \\
$0.81,2.12$
\end{tabular} & $\begin{array}{c}\text { Sm } \\
- \\
0.68,2.42 \\
0.51,2.04 \\
0.63,2.15\end{array}$ & $\begin{array}{c}\mathbf{E u} \\
- \\
1.07,2.50 \\
0.48,2.11 \\
0.62,2.21\end{array}$ & $\begin{array}{c}\text { Gd } \\
- \\
1.83,2.57 \\
0.70,2.30 \\
0.82,2.39\end{array}$ & $\begin{array}{c}\mathbf{T b} \\
- \\
1.61,2.60 \\
0.82,2.40 \\
0.90,2.46\end{array}$ & $\begin{array}{c}\text { Dy } \\
- \\
3.23,2.65 \\
1.10,2.51 \\
1.16,2.56\end{array}$ & $\begin{array}{c}\text { Ho } \\
- \\
4.18,2.65 \\
1.50,2.53 \\
1.53,2.57\end{array}$ & $\begin{array}{c}\mathbf{E r} \\
- \\
3.12,2.67 \\
1.71,2.66 \\
1.63,2.69\end{array}$ & $\begin{array}{c}\text { Tm } \\
- \\
3.35,2.67 \\
3.08,2.75 \\
2.95,2.78\end{array}$ & \begin{tabular}{|c}
$\mathbf{Y b}$ \\
$0.23,1.46$ \\
- \\
- \\
-
\end{tabular} & $\begin{array}{c}\text { Lu } \\
- \\
4.63,2.71 \\
6.62,2.86 \\
6.00,2.88\end{array}$ \\
\hline & \begin{tabular}{c|c}
$\mathbf{A c}$ \\
- \\
$0.62,1.92$ \\
$2.25,1.97$ \\
$2.95,2.07$
\end{tabular} & $\begin{array}{c}\text { Th } \\
- \\
3.98,3.62 \\
8.56,3.13 \\
12.81,3.34\end{array}$ & $\begin{array}{c}\mathbf{P a} \\
- \\
0.20,2.24 \\
1.89,3.16 \\
3.84,3.52\end{array}$ & $\mathbf{U}$ & $\mathbf{N p}$ & $\mathbf{P u}$ & Am & $\mathbf{C m}$ & $\mathbf{B k}$ & $\mathbf{C f}$ & Es & Fm & Md & No & $\mathbf{L r}$ \\
\hline
\end{tabular}

